\title{
Article
}

\section{Sex-Specific Cannabidiol- and Iloperidone-Induced Neuronal Activity Changes in an In Vitro MAM Model System of Schizophrenia}

\author{
Rachel-Karson Thériault ${ }^{1,2,+}$, Myles St-Denis ${ }^{1,+}$, Tristen Hewitt ${ }^{1,2}$, Jibran Y. Khokhar ${ }^{2,3} \mathbb{D}$, Jasmin Lalonde ${ }^{1,2} \mathbb{D}$ \\ and Melissa L. Perreault $2,3, *$ (D) \\ 1 Department of Molecular and Cellular Biology, University of Guelph, Guelph, ON N1G 2W1, Canada; \\ theriauk@uoguelph.ca (R.-K.T.); stdenis@uoguelph.ca (M.S.-D.); thewitt@uoguelph.ca (T.H.); \\ jlalon07@uoguelph.ca (J.L.) \\ 2 Collaborative Program in Neuroscience, University of Guelph, Guelph, ON N1G 2W1, Canada; \\ jkhokhar@uoguelph.ca \\ 3 Department of Biomedical Sciences, University of Guelph, Guelph, ON N1G 2W1, Canada \\ * Correspondence: perreaum@uoguelph.ca; Tel.: +1-(519)-824-4120 (ext. 52013) \\ + These authors contributed equally to this work.
}

check for

updates

Citation: Thériault, R.-K.; St-Denis, M.; Hewitt, T.; Khokhar, J.Y.; Lalonde, J.; Perreault, M.L. Sex-Specific Cannabidiol- and IloperidoneInduced Neuronal Activity Changes in an In Vitro MAM Model System of Schizophrenia. Int. J. Mol. Sci. 2021 22, 5511. https://doi.org/10.3390/ ijms22115511

Academic Editor: Felice Iasevoli

Received: 6 April 2021

Accepted: 19 May 2021

Published: 24 May 2021

Publisher's Note: MDPI stays neutral with regard to jurisdictional claims in published maps and institutional affiliations.

Copyright: (c) 2021 by the authors. Licensee MDPI, Basel, Switzerland. This article is an open access article distributed under the terms and conditions of the Creative Commons Attribution (CC BY) license (https:// creativecommons.org/licenses/by/ $4.0 /)$
Abstract: Cortical circuit dysfunction is thought to be an underlying mechanism of schizophrenia (SZ) pathophysiology with normalization of aberrant circuit activity proposed as a biomarker for antipsychotic efficacy. Cannabidiol (CBD) shows potential as an adjunctive antipsychotic therapy; however, potential sex effects in these drug interactions remain unknown. In the present study, we sought to elucidate sex effects of CBD coadministration with the atypical antipsychotic iloperidone (ILO) on the activity of primary cortical neuron cultures derived from the rat methylazoxymethanol acetate (MAM) model used for the study of SZ. Spontaneous network activity measurements were obtained using a multielectrode array at baseline and following administration of CBD or ILO alone, or combined. At baseline, MAM male neurons displayed increased bursting activity whereas MAM female neurons exhibited no difference in bursting activity compared to sex-matched controls. CBD administered alone showed a rapid but transient increase in neuronal activity in the MAM networks, an effect more pronounced in females. Furthermore, ILO had an additive effect on CBDinduced elevations in activity in the MAM male neurons. In the MAM female neurons, CBD or ILO administration resulted in time-dependent elevations in neuronal activity, but the short-term CBDinduced increases in activity were lost when CBD and ILO were combined. Our findings indicate that CBD induces rapid increases in cortical neuronal activity, with sex-specific drug interactions upon ILO coadministration. This suggests that sex should be a consideration when implementing adjunct therapy for treatment of SZ.

Keywords: schizophrenia; cannabidiol; iloperidone; haloperidol; electrophysiology; primary cortical neurons

\section{Introduction}

Schizophrenia (SZ) is a chronic psychiatric disorder characterized by positive (e.g., hallucinations) and negative (e.g., anhedonia) symptoms, as well as debilitating cognitive dysfunction [1,2]. Unfortunately, currently available antipsychotics do not adequately treat these cognitive deficits [3]. Our understanding of the disorder is further complicated by the presence of sex differences in SZ [4]. For instance, men exhibit an earlier onset and poorer course of the illness [4], while women show significantly greater improvement in overall symptom severity in response to antipsychotic treatment [5].

Cortical neuronal activity has been linked to symptoms of SZ [6-8]. As such, an emerging mechanism underlying the pathophysiology of SZ is impaired circuit activity [9]. Specifically, clinical and preclinical studies have consistently reported aberrant cortical 
synchrony, functional connectivity, or laterality in SZ, and these abnormalities have been associated with cognitive deficits $[10,11]$ and positive symptoms [8]. For instance, in a task of executive functioning and sensory processing, individuals with SZ displayed impaired cortical activity within the gamma $(30-80 \mathrm{~Hz})$ and theta $(4-8 \mathrm{~Hz})$ frequency bands, compared to healthy controls [12-17]. Thus, normalization of impaired circuit function has been proposed as a biomarker of therapeutic efficacy of antipsychotics $[18,19]$. This idea is supported by studies demonstrating that antipsychotic treatments normalize deficits in cortical activity in individuals with SZ [18] and in animal models of SZ [17,19-21]. Recently, our laboratory demonstrated that the degree of antipsychotic-induced network activity normalization in the methylazoxymethanol acetate (MAM) rat model system of $\mathrm{SZ}$ was greater with the administration of the atypical antipsychotic asenapine maleate, compared to the typical antipsychotic haloperidol (HAL) [22]. In line with this, the degree of normalization may positively correlate with improved cognitive functioning $[18,19]$, an effect that is more prominent with atypical antipsychotics than typical antipsychotics [23]. This difference in efficacy between these two drug classes is postulated to be due to the increased affinity of atypical antipsychotics for serotonin over dopamine receptors [23].

Although current antipsychotics successfully treat acute positive symptoms, long-term improvement of other symptoms, particularly negative symptoms, is low [24]. Furthermore, some atypical antipsychotics have been found to impair cognitive function in a dosedependent manner [25,26]. As such, poor treatment responses, in addition to poor insight due to illness, are the biggest contributors to the high rate of treatment non-adherence in SZ [24,27-29]. Thus, it is imperative that safe and effective treatment strategies are developed that show improved efficacy and compliance.

One promising approach has been the use of the non-psychoactive cannabinoid cannabidiol (CBD) as an adjunctive therapy for the treatment of SZ [30-34]. For instance, a recent study demonstrated that when individuals with $\mathrm{SZ}$ were given adjunctive CBD to their current antipsychotic treatment, there was an increased tolerability profile and efficacy of positive and cognitive symptom management [34]. Moreover, it has been suggested that CBD adjunctive therapy may be particularly suitable in patients that exhibit antipsychotic resistance after a case study reported the full remission of an individual with severe, antipsychotic resistant SZ following adjunctive CBD [35]. As such, CBD may complement antipsychotic treatments due to its different mechanism of action [35]. Conversely, it has also been reported that 6 weeks of added CBD treatment had no significant effect on antipsychotic-treated individuals with chronic SZ [36]. Thus, additional investigations are necessary to elucidate the effectiveness of adjunctive CBD with antipsychotics in SZ. Importantly, the impact of adjunctive CBD on antipsychotic-induced normalization of network activity in SZ is unknown.

In the present study, we sought to evaluate the effects of CBD adjunctive to the atypical antipsychotic iloperidone (ILO) on the activity of rat primary cortical neurons derived from the MAM model system of SZ and to determine whether sex-dependent effects could be detected. Comparisons to the traditional antipsychotic HAL were also performed. The findings showed that there exists sex- and model-specific drug-induced changes in neuronal systems activity, indicating that sex should be an important consideration when employing adjunct therapy, as drug interaction effects may be different.

\section{Results}

\subsection{MAM Rats Exhibit Sex-Specific Differences in Baseline Neuronal Activity}

In the present study, we sought to elucidate the impact of CBD administration alone, or with ILO, on neuronal systems activity in vitro in cortical neurons derived from the MAM model system of $\mathrm{SZ}$, and to evaluate sex differences. Using cortical neuron-glial co-cultures, we showed that neurons developed normally over the course of 4 weeks (Figure 1A,B), with a transient increase in the expression of both synapsin 1 (Syn1) and postsynaptic density 95 (PSD-95) proteins. Multielectrode array (MEA) recordings were performed on day 21 with raster plots showing baseline activity for each group (Figure 1C). Analysis of 
the firing rate (Figure 1D) showed significant sex and model effects (Sex: $\mathrm{F}(1,1156)=17.1$, $p<0.001$; Model: $\mathrm{F}(1,1156)=7.0, p<0.008)$. Female SAL neurons innately displayed lower cortical neuronal firing compared to control males $(p=0.036)$, an effect also observed between the MAM female versus MAM male neurons $(p=0.009)$. Conversely, no difference in the neuronal firing rate was evident between groups of the same sex. There was no innate difference in bursting activity between male and female SAL neurons (Figure 1E,F). However, neurons from male MAM rats exhibited elevated bursting activity compared to their SAL control counterparts ( $p<0.001$ for both number of bursts and bursting frequency). The female MAM neurons did not show this elevation in bursting and were not different from the female SAL neurons. There were no sex differences observed in the inter-burst interval with the SAL neurons (Figure $1 \mathrm{G})$. However, both male $(p<0.001)$ and female $(p=0.029)$ MAM-derived neurons showed a reduced interval compared to their samesex counterparts (Number of Bursts. Model: $\mathrm{F}(1,1156)=10.6, p=0.001$; Sex x Model: $\mathrm{F}(1,1156)=12.1, p=0.001$, Burst Frequency. Model: $\mathrm{F}(1,1104)=13.5, p<0.001$; Sex $\mathrm{x}$ Model: $\mathrm{F}(1,1104)=11.6, p=0.001$, Inter-burst Interval. Model: $\mathrm{F}(1,1072)=26.4, p<0.001)$. We next evaluated network activity and showed a lower synchrony index in the female SAL neurons compared to the other groups, and with no other group differences observed (Figure $1 \mathrm{H}$, Sex: $\mathrm{F}(1,86)=8.0, p=0.006)$. Male MAM-derived neurons showed significantly elevated network bursts compared to all other groups, with no other group differences present (Figure 1I, Sex: F $(1,92)=4.5, p=0.037$; Model: F $(1,92)=5.3, p=0.023$; Sex x Model: $\mathrm{F}(1,92)=4.50, p=0.037)$.

\subsection{Drug-Induced Effects on Neuronal Activity in Male Control Rat Cortical Neurons}

We next sought to elucidate temporal drug-induced changes in neuronal systems activity for each of the groups. Raster plots for the male SAL neurons are depicted in Figure 2A. ANOVA revealed a significant drug effect for the firing rate at $5 \mathrm{~min}(\mathrm{~F}(5,286)=3.8$, $p=0.002)$. Administration of ILO or CBD+ILO increased the mean firing rate of cortical neurons within $5 \mathrm{~min}$ with effects lost by $20 \mathrm{~min}$, such that there was no difference when compared to VEH administration (Figure 2B). A CBD-induced reduction in the firing rate of neurons was observed $24 \mathrm{~h}$ post-administration $(p=0.011)$. Similarly, ILO or CBD+ILO, or $\mathrm{CBD}+\mathrm{HAL}$, increased the number of bursts at $5 \mathrm{~min}(\mathrm{~F}(5,286)=4.8, p<0.001)$, with CBD or CBD+ILO inducing a decrease in burst number $(\mathrm{F}(5,287)=7.0, p<0.001)$ and burst frequency $(\mathrm{F}(5,246)=8.5, p<0.001)$ at $24 \mathrm{~h}($ Figure $2 \mathrm{C}, \mathrm{D})$. CBD or CBD+ILO also increased the inter-burst interval at $24 \mathrm{~h}$ post-administration compared to VEH $(p=0.016, p=0.008$, respectively, Figure 2E). When network activity was evaluated, only CBD+ILO resulted in an elevated synchrony index in the SAL male neurons $(p=0.044)$, with no drug effects on the number of network bursts at any time point (Figure 2F,G).

\subsection{Drug-Induced Effects on Neuronal Activity in Female Control Rat Cortical Neurons}

Drug effects on neuronal activity in the female SAL neurons were next evaluated with group raster plots, shown in Figure 3A. All drugs induced a transient decrease in the firing rate, number of bursts, and burst frequency, with all drugs inducing significantly reduced activity by $24 \mathrm{~h}$ (Figure 3B-D, Drug effects. Firing rate: $(\mathrm{F}(5,373)=2.2, p<0.053$; Number of bursts: $(\mathrm{F}(5,373)=5.5, p<0.001)$; Burst frequency: $(\mathrm{F}(5,354)=4.8, p<0.001)$. HAL appeared to induce these effects more rapidly, with reduced firing and bursting activity apparent within $5 \mathrm{~min}$. There were no group differences in the inter-burst interval, synchrony index, or the number of network bursts (Figure $3 \mathrm{E}-\mathrm{G}$ ). 
A

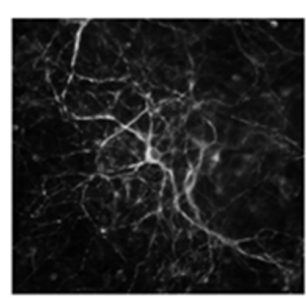

C SAL M

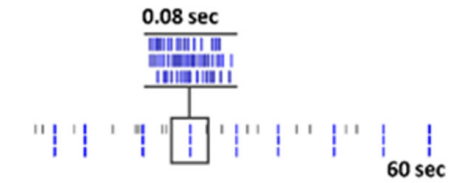

SAL F

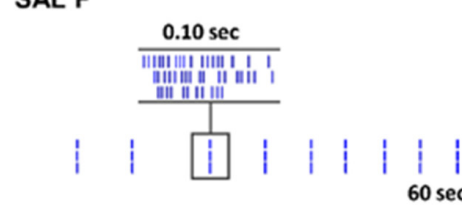

MAM M

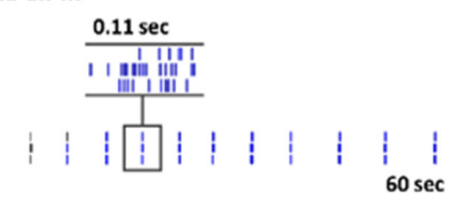

MAM F

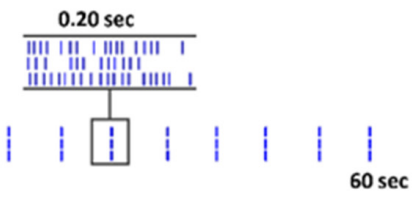

B

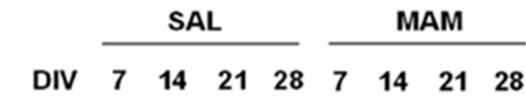

Syn1 200

Actin $-\ldots \ldots+\ldots-\ldots 2 \mathrm{kDa}$

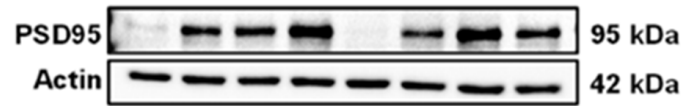

D
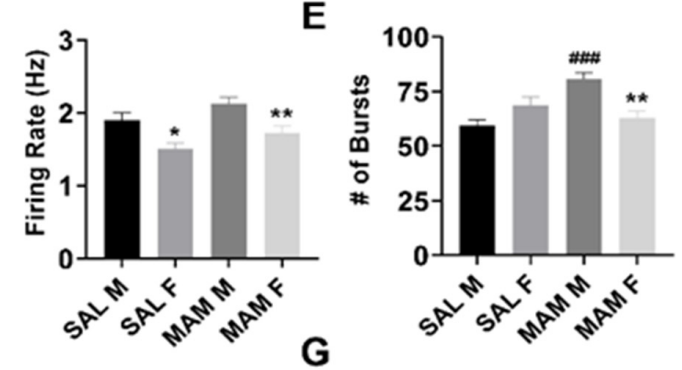

$\mathbf{F}$
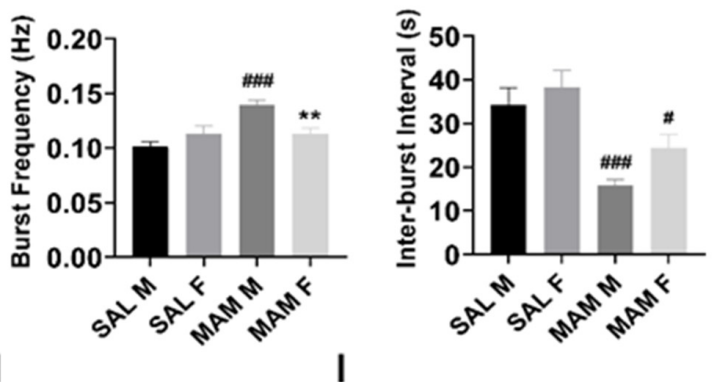

H

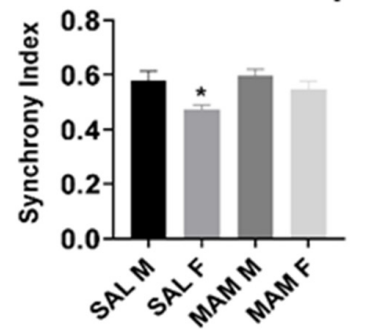

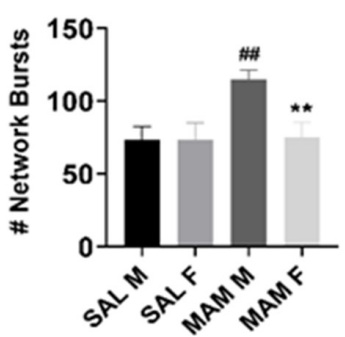

Figure 1. Effect of MAM on neuronal cortical systems activity. (A) Representative immunostaining of MAP2 showing a DIV 21 primary cortical neuron. (B) Western blot showing levels of Syn1, PSD-95 and actin at DIV 7, 14, 21, and 28 in primary cortical neurons derived from male and female SAL treated (control) and MAM rats. (C) Representative raster plots showing sex differences in baseline neuronal activity. (D) Quantification of group differences in neuronal firing rate showed that female SAL and MAM rat neurons exhibited reduced firing rates at baseline compared to male neurons of the same model. (E,F) Male MAM-derived neurons exhibited increased number of bursts compared to male SAL neurons, whereas female MAM neurons exhibited no difference in bursting activity compared to female SAL neurons. (G) Inter-burst interval showing a shorter interval in MAM-derived neurons. (H) Female SAL neurons showed a decreased synchrony index at baseline. (I) Male MAM-derived neurons exhibited elevated network bursting compared to all other groups. Data are expressed as means \pm SEM. $N=3$ biological replicates. ${ }^{*} p<0.05,{ }^{* *} p<0.01$, compared to males of the same model, ${ }^{\#} p<0.5,{ }^{\# \#} p<0.01,{ }^{\# \# \#} p<0.001$ compared to sex-matched controls, ANOVA followed by Bonferroni or Games-Howell post-hoc determined by Levene's test of variance. 
A
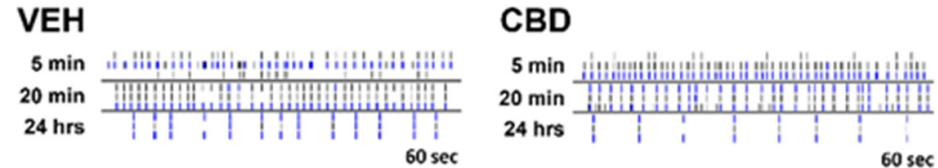

HAL

$5 \mathrm{~min}$ H!' $20 \mathrm{~min}$ Hintritem 24 hrs T'

ILO

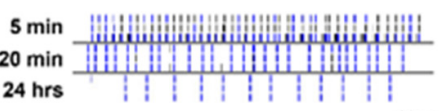

\section{CBD+HAL}

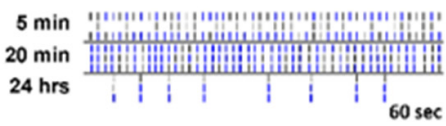

\section{CBD+ILO}

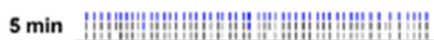

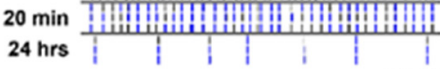

$60 \mathrm{sec}$

B

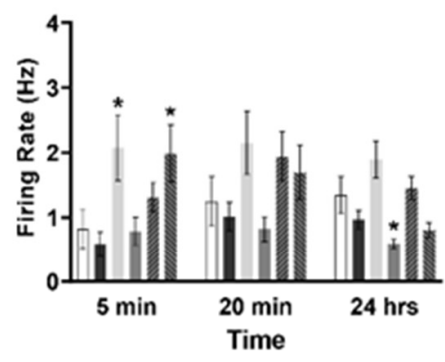

D

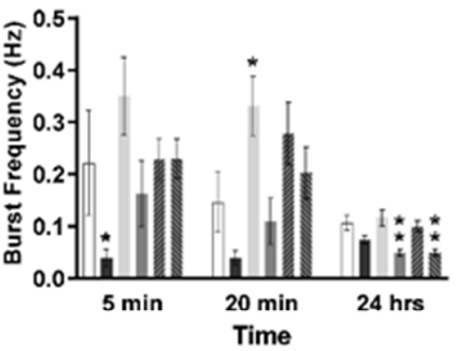

F

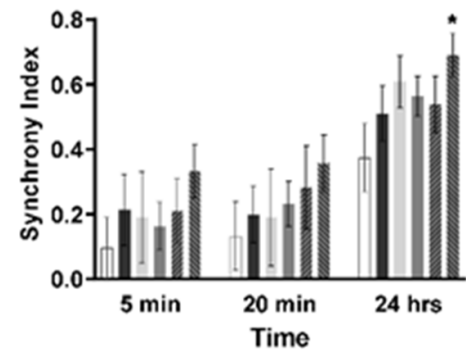

C

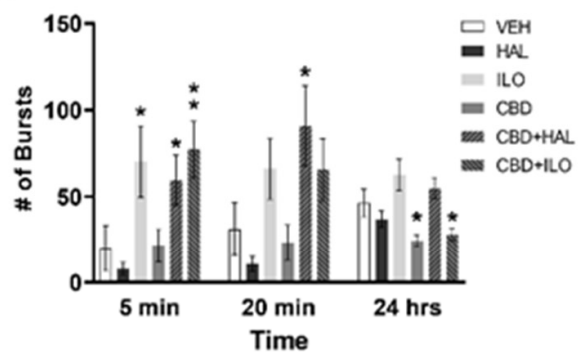

$E$

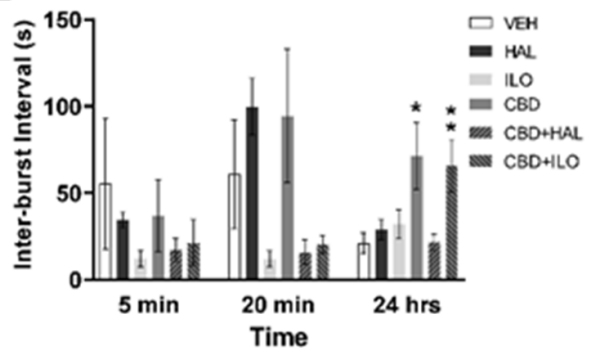

G

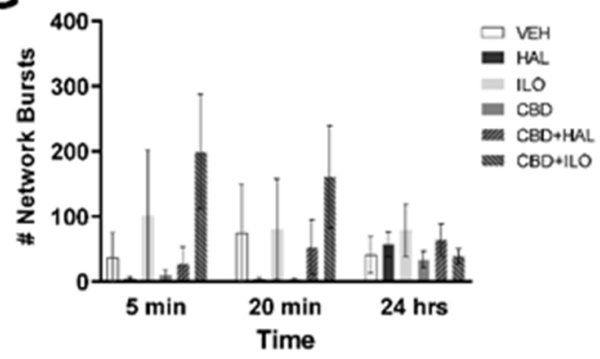

Figure 2. Temporal effect of cannabidiol (CBD) and/or antipsychotic exposure on neuronal activity in cultures derived from male SAL rats. (A) Representative raster plots showing neuronal activity following administration of each drug at $5 \mathrm{~min}, 20 \mathrm{~min}$, and $24 \mathrm{~h}$. (B) CBD or CBD+iloperidone (ILO) elevated spiking activity at $5 \mathrm{~min}$, with a reduction in spiking by CBD at $24 \mathrm{~h}$. (C) CBD alone or combined with haloperidol (HAL) or ILO increased the number of neuronal bursts at $5 \mathrm{~min}$, an effect maintained in the CBD+HAL group at $20 \mathrm{~min}$. At $24 \mathrm{~h}, \mathrm{CBD}$ or CBD+ILO groups showed reduced number of bursts. (D) HAL administration reduced burst frequency at 5 min, whereas ILO increased bursting frequency at $20 \mathrm{~min}$. At $24 \mathrm{~h}, \mathrm{CBD}$ or CBD+ILO administration suppressed bursting frequency. (E) CBD alone, or with ILO, increased the inter-burst interval at $24 \mathrm{~h}$. $(\mathrm{F}, \mathrm{G})$ Only CBD+ILO increased the synchrony index in male SAL neurons with no drug effects on the number of network bursts. Data are expressed as means \pm SEM. $\mathrm{N}=3$ biological replicates. ${ }^{*} p<0.05,{ }^{* *} p<0.01$ compared to VEH-exposed neurons, planned comparison Student's $t$-test. 
A

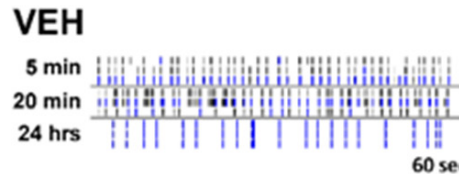

\section{CBD}

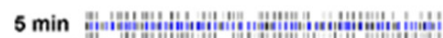

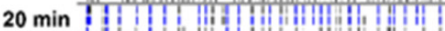

$24 \mathrm{hrs}$ || | | | | | | | |

$60 \mathrm{sec}$

HAL

$20 \mathrm{~min}$ m $24 \mathrm{mrs}$

\section{ILO}

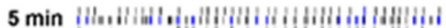
$20 \mathrm{~min}$ तामालन

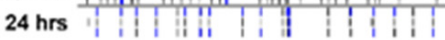

$60 \mathrm{sec}$

\section{$\mathrm{CBD}+\mathrm{HAL}$}

$5 \mathrm{~min}$ is

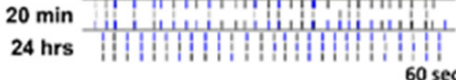

\section{CBD+ILO}

5 min $20 \mathrm{~min}$ hrs

$60 \mathrm{sec}$
B

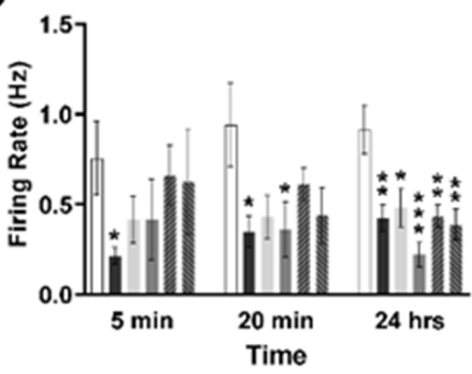

D

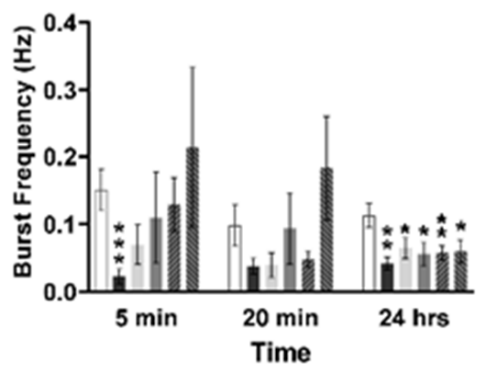

$\mathbf{F}$

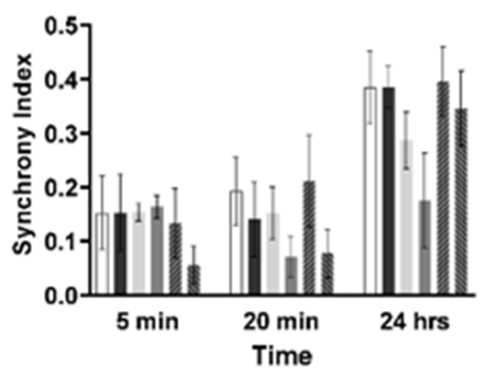

C

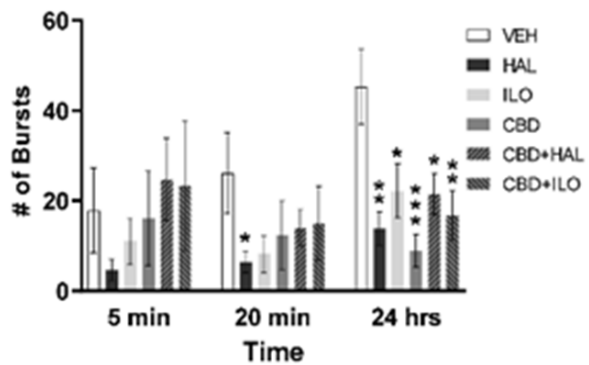

E

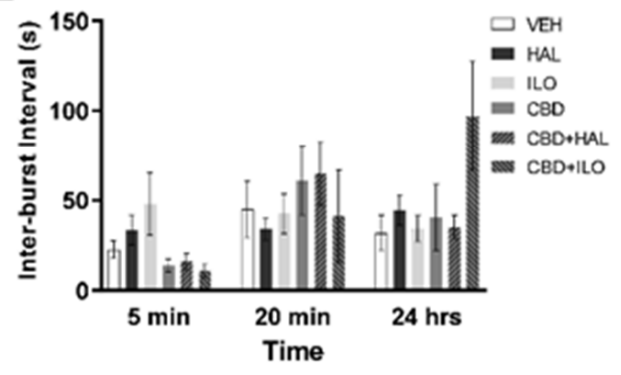

G

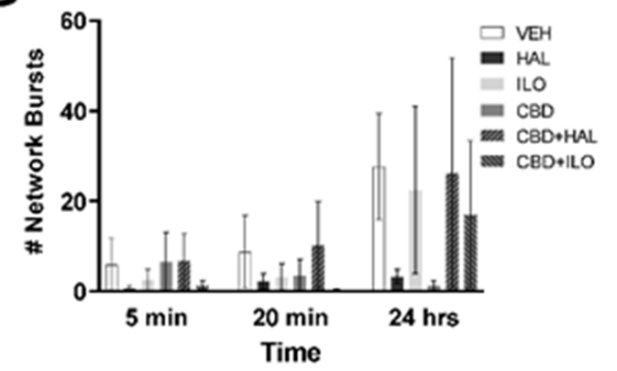

Figure 3. Temporal effect of cannabidiol (CBD) and/or antipsychotic exposure on neuronal activity in cultures derived from female SAL rats. (A) Representative raster plots following administration of each drug at $5 \mathrm{~min}, 20 \mathrm{~min}$, and $24 \mathrm{~h}$. (B-D) All drugs induced a transient decrease in firing rate, number of bursts, and burst frequency with all drugs inducing significantly reduced activity at $24 \mathrm{~h}$. However, haloperidol (HAL) showed rapid onset effects, decreasing firing and bursting activity at $5 \mathrm{~min}$. (E-G) There were no drug effects on inter-burst interval, synchrony index, or the number of network bursts at any time point. Data are expressed as means \pm SEM. $\mathrm{N}=3$ biological replicates. ${ }^{*} p<0.05,{ }^{* *} p<0.01,{ }^{* * *} p<0.001$ compared to VEH-exposed neurons, planned comparison Student's $t$-test. 


\subsection{Drug-Induced Effects on Neuronal Activity in Male MAM Rat Cortical Neurons}

The impact of CBD and/or antipsychotic administration on neuronal systems activity was next determined, with raster plots for the male MAM neurons shown in Figure 4A. There were significant drug effects evident at $5 \mathrm{~min}$ for neuronal firing rate $(\mathrm{F}(5,321)=3.5$, $p=0.004)$, number of bursts $(\mathrm{F}(5,321)=3.4, p=0.005)$, and burst frequency $(\mathrm{F}(5,268)=5.2$, $p<0.001)$. At $5 \mathrm{~min}, \mathrm{CBD}$ was the only drug, when administered alone, that affected neuronal activity (Figure 4B-D), with the exception of HAL, which reduced the inter-burst interval compared to VEH treatment ( $p=0.037$, Figure 4E). Specifically, CBD administration resulted in a higher firing rate (Figure 4B) and burst frequency (Figure 4D) of male MAM cortical neurons, with these effects exacerbated with the addition of ILO. There were no effects on the number of bursts or inter-burst interval by CBD alone; however, CBD+ILO resulted in a significant elevation in the number of bursts (Figure 4C,E). At $24 \mathrm{~h}, \mathrm{CBD}$ suppressed the number of bursts and burst frequency, similar to that observed in the male and female SAL neurons. However, these effects were not seen in the CBD+ILO group at $24 \mathrm{~h}$. For inter-burst interval, no effects were observed with any drug at any time points except for HAL alone, which induced a decrease at $5 \mathrm{~min}(p=0.041)$, and CBD+HAL, which induced an increase in the inter-burst interval at $20 \mathrm{~min}(p=0.035)$. It is also noteworthy that, unlike that observed in the SAL control neurons, when compared to baseline (Figure 1), only the addition of CBD or CBD+ILO induced an overall increase in neuronal activity in all three measures-firing rate, number of bursts, and burst frequency-at $5 \mathrm{~min}(p<0.001$ for each measure, in both groups), effects that diminished by $24 \mathrm{~h}$. Network activity analysis showed no drug-induced differences (Figure $4 \mathrm{~F}, \mathrm{G}$ ). Together, these findings demonstrate the additive effects of CBD+ILO administration in the male MAM neurons.

\subsection{Drug-Induced Effects on Neuronal Activity in Female MAM Rat Cortical Neurons}

Finally, we examined drug effects in the female MAM neurons with raster plots showing neuronal activity, depicted in Figure 5A. In these neurons, we observed significant short-term effects of CBD on neuronal activity, with CBD-induced elevations in firing rate $(p=0.017)$, burst number $(p=0.006)$, and burst frequency $(p=0.004)$ at $5 \mathrm{~min}$ compared to VEH-treated MAM neurons (Figure 5B-D, Drug effects. Firing rate: $\mathrm{F}(5,249)=4.1, p=0.001$; Number of bursts: $\mathrm{F}(5,249)=4.7, p<0.001$; Burst frequency: $\mathrm{F}(5,157)=2.4, p<0.04)$. However, when ILO was co-administered, these CBD-induced effects were abolished. HAL or ILO alone had similar effects on neuronal activity, increasing neuronal firing and/or bursting activity at $5 \mathrm{~min}$, effects also seen at $24 \mathrm{~h}$ (Drug effects. Firing rate: $\mathrm{F}(5,252)=5.0$, $p<0.001$, Number of bursts: $\mathrm{F}(5,252)=9.8, p<0.001$, Burst frequency: $\mathrm{F}(5,226)=10.3$, $p<0.001$ ). There were no drug effects observed on the inter-burst interval (Figure 5E) or on network activity (Figure 5F,G). When compared to baseline (Figure 1), the addition of CBD or ILO increased the firing rate (CBD: $p=0.04$; ILO, $p=0.02$ ), number of bursts (CBD: $p=0.001$; ILO, $p=0.03$ ), and burst frequency (CBD: $p<0.001$; ILO, $p=0.002$ ) at $5 \mathrm{~min}$, which returned to baseline levels by $24 \mathrm{~h}$. These findings demonstrate that CBD or antipsychotics alone had the most robust effects in the female MAM neurons; however, these effects were attenuated when the drugs were combined. 
A

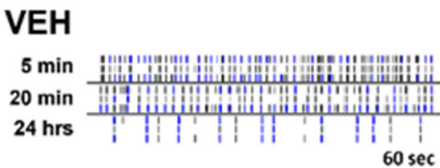

CBD

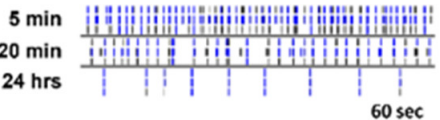

HAL

$\mathrm{CBD}+\mathrm{HAL}$

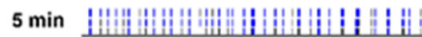

$20 \mathrm{~min}$ he hrs

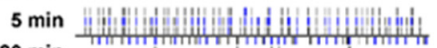

$20 \mathrm{~min}$

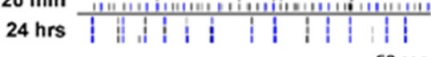

$60 \mathrm{sec}$

ILO

CBD+ILO

$5 \mathrm{~min}$ !": 4 !

$20 \mathrm{~min}$

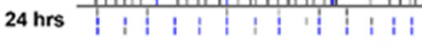

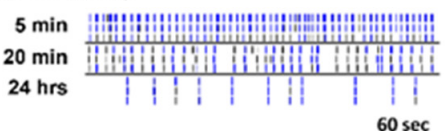

B

C

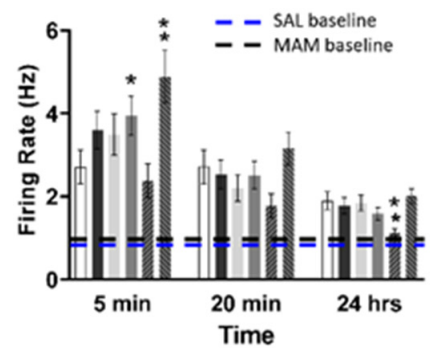

D

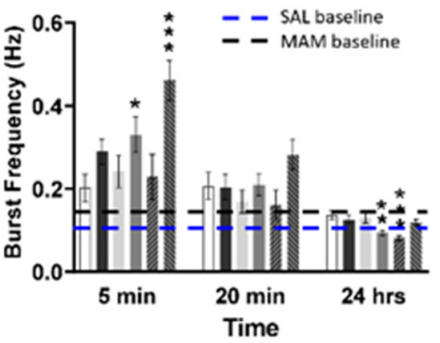

$E$
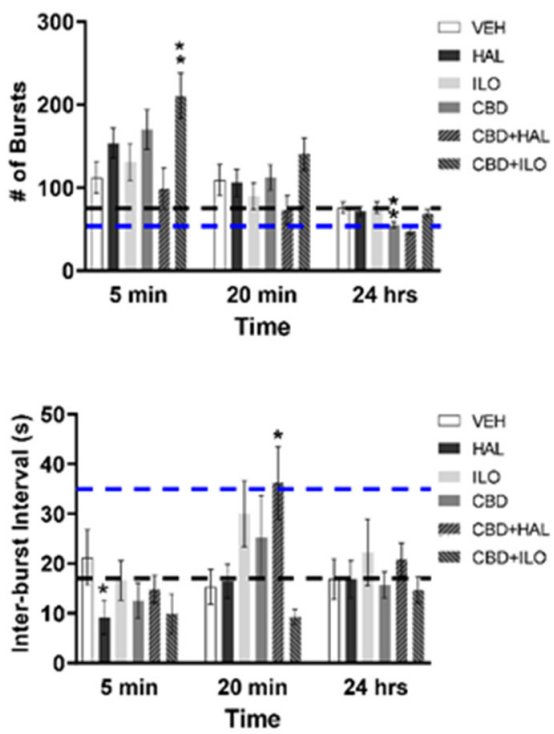

$\mathbf{F}$

G
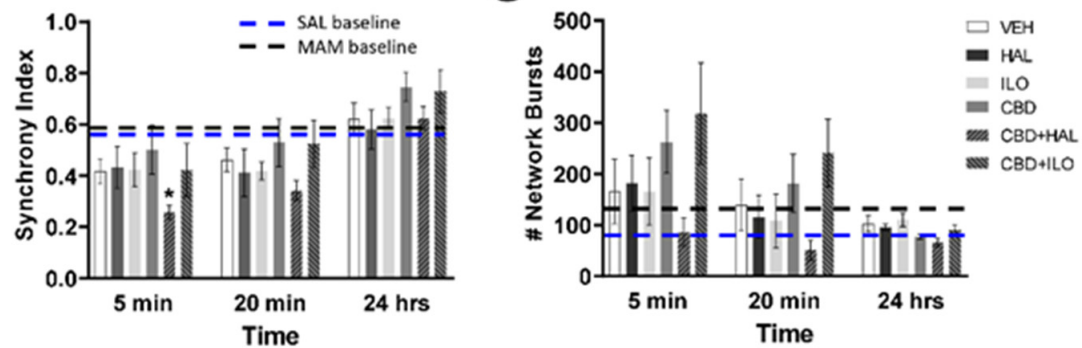

Figure 4. Temporal effect of cannabidiol (CBD) and/or antipsychotic exposure on neuronal activity in cultures derived from male MAM rats. (A) Representative raster plots following administration of each drug at $5 \mathrm{~min}, 20 \mathrm{~min}$, and $24 \mathrm{~h}$. (B) Compared to VEH-exposed neurons, at $5 \mathrm{~min}$ CBD increased the spiking rate, an effect exacerbated in the presence of iloperidone (ILO). At $24 \mathrm{~h}, \mathrm{CBD}+$ haloperidol (HAL) administration lowered the spiking rate. (C) CBD+ILO increased the number of bursts at $5 \mathrm{~min}$, with CBD alone suppressing burst number at $24 \mathrm{~h}$. (D) CBD or CBD+ILO increased the bursting frequency at $5 \mathrm{~min}$, with $\mathrm{CBD}$ or $\mathrm{CBD}+\mathrm{HAL}$ lowering it at $24 \mathrm{~h}$. (E) HAL alone resulted in a lower inter-burst interval at $5 \mathrm{~min}$, whereas CBD+HAL elevated it at $20 \mathrm{~min}$. (F) CBD+HAL suppressed the synchrony index at $5 \mathrm{~min}$. (G) There were no drug effects on the number of network bursts. SAL- and MAM-derived baseline data is depicted by the blue and black dashed lines, respectively. Data are expressed as means \pm SEM. $N=3$ biological replicates. ${ }^{*} p<0.05,{ }^{* *} p<0.01,{ }^{* * *} p<0.001$ compared to VEH-exposed neurons, planned comparison Student's $t$-test. 
A

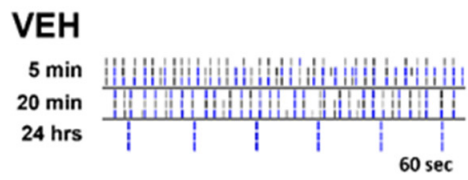

CBD
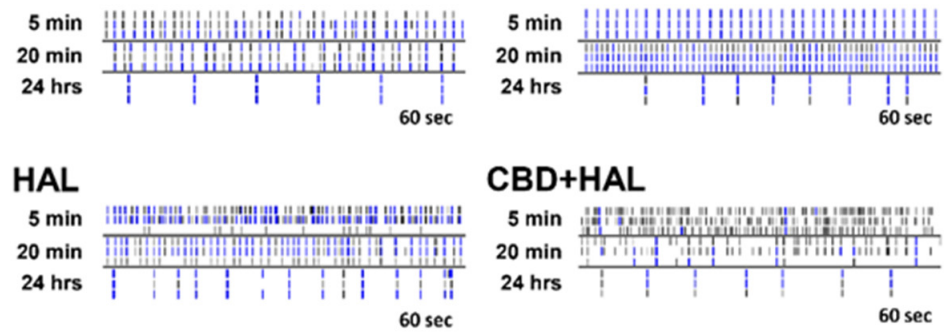

CBD+HAL
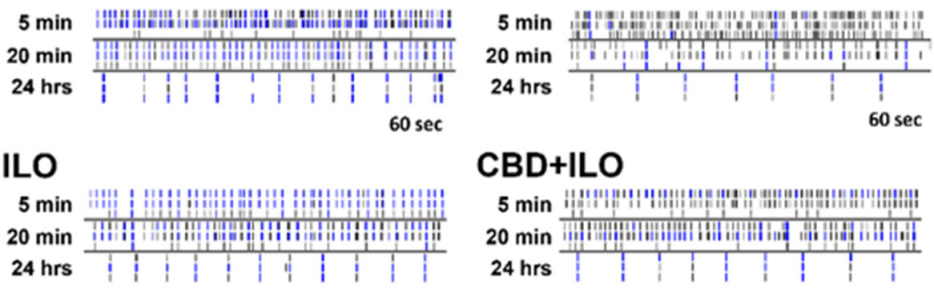

\section{CBD+ILO}

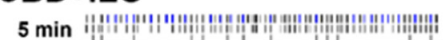
$20 \mathrm{~min}$. Hon

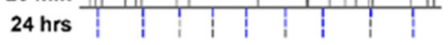

B $60 \mathrm{sec}$ $60 \mathrm{sec}$

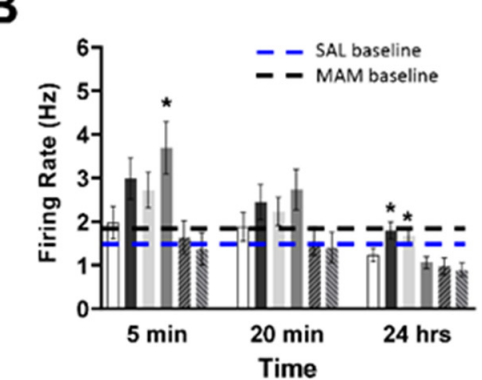

\section{C}

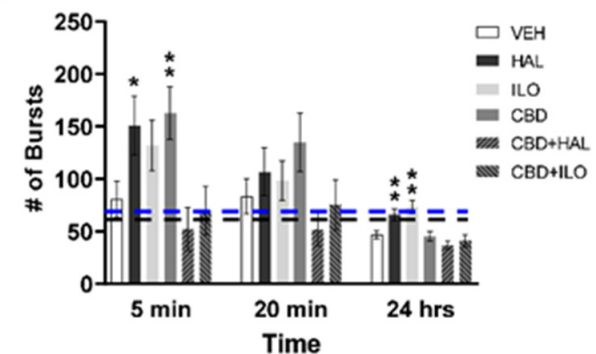

D

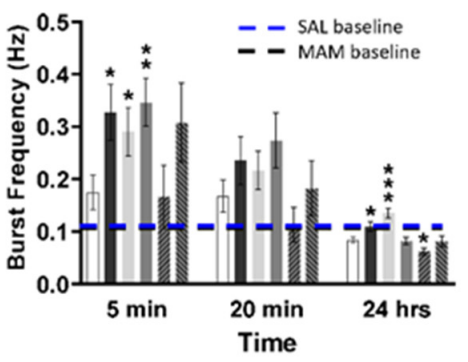

E

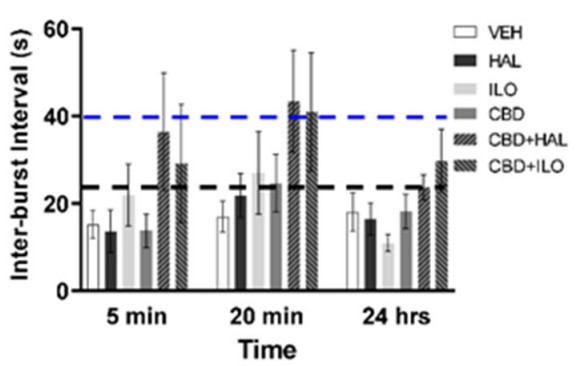

$\mathbf{F}$

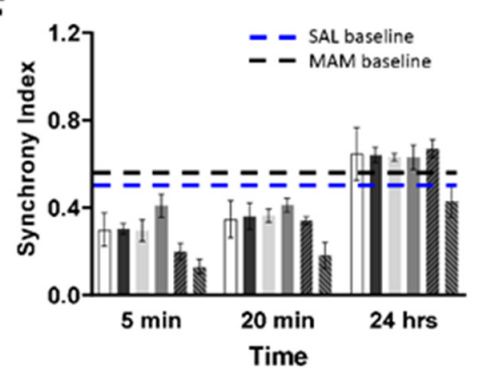

G

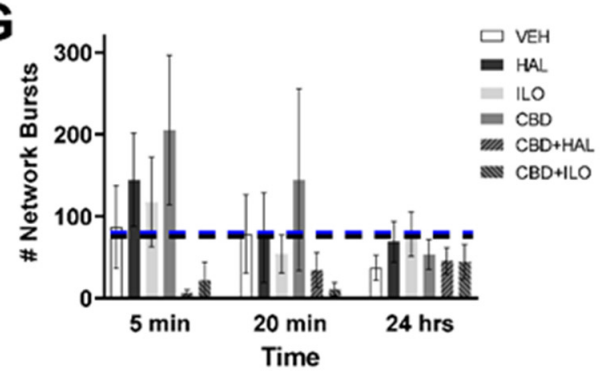

Figure 5. Temporal effect of cannabidiol (CBD) and/or antipsychotic exposure on neuronal activity in cultures derived from female MAM rats. (A) Representative raster plots following administration of each drug at $5 \mathrm{~min}, 20 \mathrm{~min}$, and $24 \mathrm{~h}$. (B) CBD exposure resulted in a higher firing rate at $5 \mathrm{~min}$ compared to VEH. Haloperidol (HAL) or iloperidone (ILO) increased the firing rate at $24 \mathrm{~h}$. (C,D) $\mathrm{HAL}$ or CBD alone resulted in an elevated number of bursts and bursting frequency at $5 \mathrm{~min}$. ILO administration also elevated the bursting frequency at this time point. At $24 \mathrm{~h}$, HAL or ILO elevated both the number of bursts and the bursting frequency. (E-G) There were no drug effects observed at any time point on the inter-burst interval, synchrony index, or number of network bursts. SAL- and MAM-derived baseline data is depicted by the blue and black dashed lines, respectively. Data are expressed as means \pm SEM. $\mathrm{N}=3$ biological replicates. ${ }^{*} p<0.05,{ }^{* *} p<0.01,{ }^{* * *} p<0.001$ compared to VEH-exposed neurons, planned comparison Student's $t$-test. 


\section{Discussion}

The present study aimed to delineate the temporal and sex-dependent effects of acute $\mathrm{CBD}$, alone or in combination with HAL or ILO, on neuronal activity of primary cortical neurons derived from the MAM neurodevelopmental animal model of SZ. We demonstrated that at baseline, exposure to MAM in the dams significantly increased bursting activity in primary neurons derived from the male offspring, while female offspringderived cultures exhibited no change, compared to their sex-matched SAL control groups. When administered alone, CBD induced a rapid and transient increase in neuronal activity in the MAM-derived cultures. Further, this transient increase in neuronal activity was additive when CBD was combined with ILO in MAM male neurons only. Conversely, in MAM females, co-administration of CBD with ILO abolished the effects observed when $\mathrm{CBD}$ was given alone. Collectively, these results suggest that $\mathrm{CBD}$ may elicit rapid effects through increased neuronal activity, although adjunctive CBD therapy may have differential effects in males and females. Thus, sex should be a consideration when employing combination therapy.

Baseline recordings of cortical neurons indicated sex differences in the activity of MAM-derived cultures, whereby males showed increased bursting while both males and females exhibited a decreased inter-burst interval, relative to sex-matched control cultures. The majority of studies have reported reduced spontaneous and evoked network activity, mean firing frequencies and average burst duration in cortical [37-39] and hippocampal (HIP) human-induced pluripotent stem cells (hiPSC) derived from SZ patients [40]. However, evidence of increased bursting and spontaneous network activity has also been found in SZ mouse model-derived HIP cultures [41] and SZ patient-derived cortical hiPSCs [42]. Notably, these studies did not examine whether the results were influenced by sex; therefore, we propose that the sex-dependent effects in our study may provide insights into the conflicting reports thus far.

It is well documented that there are prominent sex differences in $\mathrm{SZ}$ at both the clinical and physiological levels $[4,43,44]$. The incidence of SZ in men to women is 1.4:1 and the peak age of onset for SZ in men is in their early twenties. In women, although the incidence is less than that of men, the peak age of onset is later, being highest in their twenties and with an additional peak in onset in midlife, where women exhibit a higher incidence than males $[4,45]$. Men are also known to exhibit a more severe phenotype of the disease, with more severe negative and cognitive symptoms compared to women, whereas women exhibit more severe mood-related symptoms [4]. The long-term prognosis for $\mathrm{SZ}$ also differs between men and women, with women displaying superior long-term outcomes and responses to antipsychotic treatment $[4,46]$. Furthermore, adverse side effects of antipsychotic medications are also more prevalent in women [47]. Evidence from individuals with SZ also indicates that there are sex-dependent genetic risk factors [44], and sex differences in the serum concentrations of multiple molecules associated with inflammatory, hormonal, and growth factor signalling pathways that have been correlated to symptom severity [43]. Sex differences at the cellular and molecular level have also been reported in animal models of SZ. In the prenatal immune challenge model of SZ in mice, for example, distinct sex differences were found in microglial distribution, process arborization, oxidative stress, synaptic function, and expression of inflammatory genes that may be relevant to the increased incidence of severe SZ in males [48]. In the MAM model of SZ in mice, sex differences have been reported not only in neuronal activity, but also in the expression of regulatory proteins, primarily those involved in glutamatergic signaling in the prefrontal cortex [49]. While glutamatergic transmission drives excitation in cortical circuits, inhibition from gamma aminobutyric acid (GABA)ergic interneurons plays a key role in regulating excitability of pyramidal neurons in order to generate synchronized firing patterns required for efficient communication between neuronal ensembles [11]. Post-mortem analysis of the cingulate cortex of individuals with SZ revealed decreased and increased expression levels of GABAergic genes in men and women, respectively, compared to sex-matched controls [50]. Further, cortical GABAergic interneurons that express 
parvalbumin, critical regulators of activity balance in SZ [37], are reduced in number [51]. To our knowledge, sex differences in parvalbumin expression have not yet been evaluated in humans, although some findings have shown sex-specific differences in the MAM rodent model of SZ. For example, a decrease in parvalbumin-positive interneurons, in line with those observed in human SZ patients, in both MAM-treated male and female rats has been shown [10,52]. Conversely, Chalkiadaki et al. [49] found that MAM exposure decreased the expression of parvalbumin in male but not in female mice, and that only male mice exhibited prefrontal cortical deficits in activity, a discrepancy that may be explained by the different species employed.

In this study, we observed sex- and model-specific effects in response to CBD administration alone. Both male and female MAM-derived cultures displayed rapid increases in neuronal activity, as evidenced by an elevation in the mean firing rate, number of bursts, and burst frequency in response to CBD that were absent in the SAL culture neurons. Interestingly, these effects were also present with ILO alone in the female MAM cultures. These findings may not only indicate potentially increased sensitivity of the MAM cultures to CBD, but a sex-specific sensitivity to ILO. At $24 \mathrm{~h}$ post-administration, however, decreased activity was evident in both male MAM- and SAL-derived cultures. In the female neurons, only the SAL-derived cultures showed suppressed activity, which occurred as early as 20 min post-drug exposure. These results indicate that CBD may have unique effects in healthy individuals versus those with an underlying disorder such as $\mathrm{SZ}$ and, further, that this may occur in a sex-specific manner. Despite evidence of sex differences in the effects of cannabinoids such as THC, evidence of sex differences in the biological responses to CBD are lacking [53]. Additionally, evidence of CBD effects on network activity is also sparse. However, electroencephalographic (EEG) and functional magnetic resonance imaging (fMRI) studies have reported altered functional connectivity patterns and network integration following a month of CBD treatment in healthy participants [54,55]. Although the functional relevance of these findings is unknown, they support CBD-induced alterations in synchronized neural activity [54]. To our knowledge, our findings are the first to demonstrate transient increases in neuronal activity following CBD administration in cortical neurons derived from the MAM model of $\mathrm{SZ}$, and we postulate that these alterations may be linked to the rapid physiological effects known to accompany CBD exposure $[56,57]$. Chronic CBD monotherapy has been demonstrated to exert antipsychotic properties in clinical studies $[33,58]$, as well as ameliorate social and cognitive deficits in rodent models of SZ [59-62].

Interestingly, when administered alone, HAL and ILO showed minimal to no significant effect on neuronal activity in MAM male neurons but increased burst frequency, number of bursts, and firing rate in MAM female neurons. This finding may suggest a greater biological impact of antipsychotics in women than in men, and is in line with clinical findings showing that women respond better to antipsychotic treatment than men [4]. Further, this antipsychotic-induced increase in neuronal activity supports a previous MEA study in primary cortical neurons of wild-type (WT) mice, which reported that acute therapeutic doses of typical and atypical antipsychotics increased network-wide temporal synchronization [63]. Other MEA studies have found increased neuronal activity and synchronization with atypical antipsychotics only, and alterations in the opposite direction occurring with HAL exposure [64,65]. However, this discrepancy is likely a result of these experiments having been conducted in rodent primary HIP cultures and/or the model system used [64,65]. Interestingly, the enhanced activity in MAM femalecultures was maintained $24 \mathrm{~h}$ post-administration of antipsychotics, with trends evident at $20 \mathrm{~min}$. This is in line with past evidence of antipsychotic-induced increases in neuronal activity at $10 \mathrm{~min}$ post-administration [63], and follows the pharmacological timelines observed in clinical studies. Specifically, within $24 \mathrm{~h}$ of receiving HAL or atypical antipsychotic medication, individuals with SZ displayed significantly increased dopamine receptor blockade [66,67], as well as improved positive symptoms [68]. Therefore, it is possible that the network alterations we observed at $24 \mathrm{~h}$ post-administration are therapeutically relevant. 
Evidence suggests that positive long-term effects of antipsychotic drugs may be attributed to changes in synaptic plasticity $[69,70]$. For instance, antipsychotics are thought to induce changes in synaptic function, and subsequent network activity, through modulating the expression of synaptic proteins, dendritic branch structure, and spine density $[64,65,70,71]$. Evidence of these effects are most understood in the context of chronic treatment; however, there is evidence of acute exposure to antipsychotics modifying dendritic morphology, thereby influencing synaptic function. Acute administration of HAL and atypical antipsychotics was shown to increase dendritic complexity in primary striatal

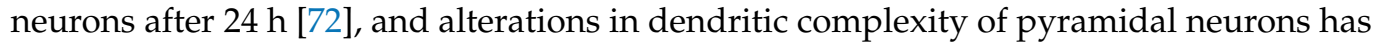
been associated with modified neuronal activity [73-75]. Acute treatment with the atypical antipsychotic olanzapine was also shown to reverse spine density deficits in an animal model of SZ and required chronic treatment to maintain this effect [76]. Furthermore, studies of immediate-early genes (IEGs) suggest that the activation of IEGs with acute antipsychotic treatment plays a key role in mediating their acute therapeutic effects and may set in motion the long-term changes associated with chronic treatment [77]. Although in the present study, increased activity with HAL and ILO administration was observed in MAM-derived female cultures only, this discrepancy could be explained due to many of these studies modeling repeated exposure to antipsychotic drugs over multiple days. It is noteworthy, however, that this observation in MAM female cultures could indicate that females are also more sensitive to the sustained effects of antipsychotic drugs.

As previously mentioned, adjunctive CBD therapy is a promising new approach for the treatment of SZ. Recent clinical studies have found significantly improved medication tolerability, positive symptoms, and cognitive dysfunction, with a trend of ameliorated negative symptoms, in SZ patients given adjunctive CBD [34,35]. However, support for a lack of significant effect of CBD on antipsychotic-treated individuals with chronic SZ has also been reported [36]. Our results suggest that the discrepancy in findings may be, at least in part, tied to sex differences. Specifically, in male MAM neurons, the combination of CBD with ILO appeared to have an additive effect, with a rapid and transient increase in neuronal activity having been observed. Although CBD with HAL was observed to induce a sustained decrease in bursting activity approaching baseline activity in SAL males at 24 $h$, this could simply be attributed to the effects of CBD, as this was also observed with CBD administration alone and not HAL. Conversely, while exposure to CBD or antipsychotics alone caused a transient increase in activity in MAM females, combination administration abolished the effects of either drug at all time points. Taken together, these results may indicate that CBD adjunctive therapy is more beneficial in males than females, although this hypothesis assumes that the increased neuronal activity is indeed therapeutic. As such, future studies are warranted to link these drug-induced changes in network activity with behavioural output.

It is worth noting that cortical neuron-glial co-cultures were utilized in the present study to better emulate in vivo conditions. It is well known that $\mathrm{SZ}$ is associated with neuroinflammation and the elevation of pro-inflammatory cytokines is associated with more severe presentation of symptoms [78-81]. HAL, atypical antipsychotics, and CBD have all been demonstrated to inhibit the release of pro-inflammatory cytokines in vitro [82-87]. The anti-inflammatory effects of these drugs, and CBD in particular, are thought to account in part for their therapeutic effects $[60,82,88]$. Activation of glial cells and subsequent proinflammatory cytokine cascades are known to influence the activity and function of neural networks through modulation of synaptic plasticity [89-91]. Furthermore, both microglia and astrocytes are now known to play a key role in regulating synaptic transmission [92-96]. Microglia have been shown to detect synaptic activity and modulate synaptic remodelling through multiple mechanisms [94-96]. Notably, microglial secretion of the cytokine TNF- $\alpha$ is known to play a key role in synaptic scaling, a key mechanism for maintaining homeostatic activity through modulation of glutamatergic signalling [95-97]. Although it is unclear whether CBD produces antipsychotic effects mediated through microglia in the absence of pathological microglial activation, the effects of CBD monotherapy observed in 
the present study may be partly attributed to its effects on the functioning of astrocytes. Although the mechanisms by which CBD modulates the activity of astrocytes are not well understood at this time, CBD has been shown to increase production of the endogenous cannabinoid anandamide [33], which is known to activate CB1 receptors to increase the release of glutamate from astrocytes, thus increasing glutamatergic transmission $[93,98,99]$. Indeed, the increased expression of CB1 receptors has been found in patients with SZ and in the prefrontal cortex of MAM model rats [100].

Although this study provides important insights into sex differences in CBD and antipsychotic effects, it is important to highlight limitations associated with our experimental approach. First, this study was conducted in vitro, which does not mimic the environment and intricate neuronal networks that are present in in vivo model systems. For example, structural and functional laterality are hallmarks of SZ [8,101] that may also exhibit sex differences [101] and which cannot be captured in in vitro systems. Second, the behavioural output associated with the changes in neuronal activity cannot be assessed and therefore, the functional relevance can only be postulated. Third, only short-term drug effects were examined and chronic treatment of SZ is required in the clinical setting [102]. Consequently, whether the alterations we observed with acute CBD and antipsychotics are sustained with long-term treatment is not known and should be the focus of future studies. In summary, it is clear that more studies are required to fully elucidate the impact of adjunctive CBD therapy on network activity in $\mathrm{SZ}$ and the associated sex differences and behavioural effects. In this study, our findings suggest that CBD or ILO administration alone may be more relevant in women with SZ in the context of neuronal activity, while men with SZ may benefit more from CBD adjunctive therapy with ILO. This highlights that sex should be included as a critical factor when determining treatments and that sex differences should be assessed in future studies.

\section{Materials and Methods}

\subsection{Animals}

Six pregnant Sprague-Dawley rats (Charles River, QC, Canada) were injected with MAM (22 mg/kg, intraperitoneally (i.p.)) or saline (SAL) at a volume of $1 \mathrm{~mL} / \mathrm{kg}$ on gestational day 17, as previously described [22]. Rats were provided food and water ad libitum and maintained on a $12 \mathrm{~h}$ reverse light-dark cycle ( $0800 \mathrm{~h}$ lights off; $2000 \mathrm{~h}$ lights on). All procedures were in accordance with the guidelines defined by the Guide to the Care and Use of Experimental Animals (Canadian Council on Animal Care, 1993) and the Animal Care Ethics Committee of the University of Guelph (protocol number: AUP\#3734, approved 18 January 2018).

\subsection{Cell Culture}

Cortical neuronal glial co-cultures were prepared from postnatal day 0-1 Sprague Dawley rat pups. Pups were euthanized by decapitation and their brains were dissected out of the skull in ice-cold dissecting media (1X HBSS, 1\% 1M HEPES, 1\% penicillin/streptomycin; all Gibco, Fisher Scientific, Mississauga, ON, Canada) in a glass petri dish. The meninges were removed and cerebral cortices were isolated and processed individually. Following three washes in dissecting media, the cortices were digested using 2.5\% Trypsin (Gibco) at $37^{\circ} \mathrm{C}$ for $20 \mathrm{~min}$, inverting halfway through. The cortices were then washed twice in dissecting media, triturated, and passed through a $100 \mu \mathrm{m}$ pore falcon cell strainer (Fisher Scientific, Ottawa, ON, Canada). Following centrifugation of the samples $(200 \times g$ at room temperature), the supernatant was aspirated and the cells were resuspended in plating media (Neurobasal medium (Gibco), 5\% fetal calf serum (Cytiva, Mississauga, ON, Canada), 2\% B27 supplement (Gibco), 1\% penicillin/streptomycin (Gibco), and 1\% $200 \mathrm{mM} \mathrm{L-glutamine}(\mathrm{Gibco})$ ). Cells were plated at a density of $3.0 \times 10^{5}$ cells/well onto 24-well CytoView MEA plates (Axion Biosystems, Atlanta, GA, USA) for electrophysiological recordings, $1.5 \times 10^{5}$ cells/well onto Corning 24-well plates with $12 \mathrm{~mm}$ glass cover slips (Fisher Scientific, Ottawa, ON, Canada) for immunocytochemistry, and 
$1.0 \times 10^{6}$ cells / well onto Corning 6-well plates for Western blotting. All plates were coated with $0.1 \mathrm{mg} / \mathrm{mL}$ poly-D-lysine (Sigma-Aldrich, Oakville, ON, Canada) and $2.5 \mu \mathrm{g} / \mathrm{mL}$ laminin (Sigma-Aldrich). Half-media changes were performed with serum-free media (Neurobasal Medium, 2\% B27 supplement, 1\% penicillin/streptomycin and 1\% 200mM L-glutamine; Gibco) 3 hours after plating and every 3-4 days throughout the period of culture. Electrophysiology and immunocytochemistry experiments were carried out on day in vitro (DIV) 21, while cultures were maintained up to DIV 28 for Western blotting.

\subsection{Drugs and Treatment of Cell Cultures}

MAM was purchased from MRI Global (Kansas City, MO, USA). ILO (Sigma-Aldrich, Oakville, ON, Canada), HAL (Sigma-Aldrich, Oakville, ON, Canada), and CBD (Toronto Research Chemicals, North York, ON, Canada) were dissolved as stocks in DMSO to a concentration of $1 \mathrm{mM}$ (ILO, HAL) or $10 \mathrm{mM}$ (CBD). For all experiments, fresh serum free medium supplemented with compounds was added directly to well with cells. Final concentrations for ILO and HAL was $100 \mathrm{nM}(0.02 \%$ DMSO $)$ and $1 \mu \mathrm{M}(0.02 \%$ DMSO $)$ for CBD. These concentrations were based on previous studies $[64,103]$.

\subsection{MEA Recordings}

All MEA readings were performed using the Maestro Edge multi-well MEA recorder (Axion Biosystems, Atlanta, GA, USA) and recorded with the Maestro system and Axion's Integrated Studio (AxIS, Axion Biosystems, Atlanta, GA, USA) software configured to neuronal-spontaneous activity. Active electrodes were defined as $>5$ spikes $/ \mathrm{min}$ across wells. Plates were maintained at $37^{\circ} \mathrm{C}$ for the duration of recordings. Electrical activity was recorded for $10 \mathrm{~min}$ prior to drug treatments, as well as $5 \mathrm{~min}, 20 \mathrm{~min}$, and $24 \mathrm{~h}$ post-drug administration. Recordings were taken at a sampling rate of $12.5 \mathrm{kHz}$, a gain of 1000 times, and a spike detection threshold of 6 times standard deviation. Burst detection criteria was defined as having a maximum inter-spike interval of $100 \mathrm{msec}$ and a minimum of 5 spikes. Network burst detection criteria was set to a maximum inter-spike interval of $100 \mathrm{~ms}$, a minimum of 50 spikes and at least 35\% of active electrodes spiking simultaneously. Spike files were processed and analyzed using the NeuralMetric Tool software (Axion Biosystems, Atlanta, GA, USA).

\subsection{Immunocytochemistry}

Immunocytochemistry was performed as done previously [104]. In each well, $500 \mu \mathrm{L}$ of media was replaced with $8 \%$ paraformaldehyde and then incubated for $30 \mathrm{~min}$ at room temperature. After fixation, cells were washed three times in 1X phosphate-buffered saline (PBS) for $10 \mathrm{~min}$ and then blocked in 5\% non-fat milk, $4 \%$ bovine serum albumin (BSA) (Thermo Fischer Scientific, Canada) and 0.1\% Triton x100 (Fisher Scientific, Ottawa, ON, Canada) in 1X PBS for $60 \mathrm{~min}$ at room temperature. Cells were immunostained with a primary antibody for MAP2 (1:1000, Sigma-Aldrich, Oakville, ON, Canada), followed by secondary donkey anti-rabbit Alexa Fluor 594 (1:500, Invitrogen, Life Technologies, Burlington, ON, Canada), Alexa Fluor 488 phalloidin (100 nM, Invitrogen), and DAPI $(1 \mu \mathrm{g} / \mathrm{mL}$; Cell Signaling, Whitby, ON, Canada). Cover slips with cultured cortical networks were mounted on microscope slides with Prolong Gold (Invitrogen) overnight at $4{ }^{\circ} \mathrm{C}$ and subsequently imaged using a Nikon Eclipse Ti2 at 20 times magnification.

\subsection{Western Blotting}

For Western blot analyses, cells were collected in ice-cold RIPA buffer (Sigma-Aldrich, Oakville, ON, Canada) with added phosphatase and protease inhibitors. Samples were centrifuged at $17,530 \times g$ for $15 \mathrm{~min}$ at $4{ }^{\circ} \mathrm{C}$, supernatants were transferred to a fresh tube, and lysates were stored in aliquots at $-80^{\circ} \mathrm{C}$ until time of analysis. Protein concentrations were determined using the Bradford assay (Bradford, 1976). Protein samples $(20 \mu \mathrm{g})$ were loaded onto a $10 \%$ sodium dodecyl sulfate (SDS) polyacrylamide gel for electrophoresis at $100 \mathrm{~V}$ using a Mini-PROTEAN Tetra cell system (Bio-Rad, Mississauga, ON, Canada). 
Proteins were then transferred at $25 \mathrm{~V}$ for 30 min onto polyvinylidene difluoride (PVDF) membrane (Bio-Rad, Mississauga, ON, Canada) using a Trans-Blot SD Turbo apparatus (Bio-Rad). Membranes were briefly washed in tris-buffered saline (TBS) with $0.1 \%$ Tween20 (TBS-T) and then blocked in either $5 \%$ non-fat milk or 5\% BSA (Fisher Scientific, Ottawa, ON, Canada) in TBS-T for $1 \mathrm{~h}$ at room temperature. Following blocking, membranes were washed twice with TBS-T and incubated overnight at $4{ }^{\circ} \mathrm{C}$ in primary antibody specific for either PSD-95 (1:1000, Cell Signaling, Whitby, ON, Canada), synapsin-1 (1:10,000,New England Biolabs, Whitby, ON, Canada), or $\beta$-actin (1:10,000, Abcam, Toronto, ON, Canada). Blots were washed three times with TBS-T, incubated with anti-rabbit horseradish peroxidase (HRP)-conjugated polyclonal secondary antibody (1:6000; Bio-Rad, Mississauga, ON, Canada) in milk or BSA for $1 \mathrm{~h}$ at room temperature, and then washed three times with TBS-T. Bands were visualized using enhanced chemiluminescence (ECL) (Bio-Rad) on a ChemiDoc MP imaging system (Bio-Rad, Mississauga, ON, Canada).

\subsection{Statistical Analysis}

Prior to all analyses, a Shapiro-Wilk test was used to assess normality and differences in group variance assessed by Levene's test. Baseline measurements for each experimental group were taken from all active electrodes across each plate. Following drug treatment, activity measures were calculated using data from all active electrodes in each of the 4 wells. The mean firing rate, number of bursts, inter-burst interval, and burst frequency were calculated using data from all active electrodes within a treatment group whereas number of network bursts and synchrony index were calculated using the mean from each well with more than 6 active electrodes. Baseline data was analyzed using a two-way analysis of variance (ANOVA) with sex and model as between-subject effects, and significant between group differences determined by Bonferroni or Games-Howell post-hoc tests as appropriate. Post-drug administration data were analyzed at each time point using a one-way ANOVA, with treatment as a between-subjects variable, followed by planned comparisons using Student's $t$-test. Computations were performed using IBM SPSS 27 software and are expressed as mean $\pm \mathrm{SEM}$. Statistical significance was defined as $p<0.05$.

Author Contributions: Conceptualization, J.Y.K. and M.L.P.; Data curation, R.-K.T. and M.S.-D.; Funding acquisition, M.L.P.; Investigation, R.-K.T., J.L., and M.L.P.; Methodology, M.S.-D. and T.H.; Project administration, M.L.P.; Resources, J.Y.K., J.L., and M.L.P.; Supervision, J.L. and M.L.P.; Visualization, T.H.; Writing-original draft, R.-K.T. and M.S.-D.; Writing—review \& editing, R.-K.T., J.Y.K., J.L., and M.L.P. All authors have read and agreed to the published version of the manuscript.

Funding: This research was funded by the Natural Sciences and Engineering Research Council, grant number 401359 (to MLP).

Institutional Review Board Statement: In accordance with the guidelines defined by the Guide to the Care and Use of Experimental Animals (Canadian Council on Animal Care, 1993) and the Animal Care Ethics Committee of the University of Guelph (protocol number: AUP\#3734, approved 18 January 2018).

Data Availability Statement: Data will be made available upon reasonable request.

Conflicts of Interest: The authors declare no conflict of interest.

$\begin{array}{ll}\text { Abbreviations } \\ \text { CBD } & \text { Cannabidiol } \\ \text { HAL } & \text { Haloperidol } \\ \text { ILO } & \text { Iloperidone } \\ \text { MAM } & \text { Methylazoxymethanol Acetate } \\ \text { SAL } & \text { Saline } \\ \text { SZ } & \text { Schizophrenia } \\ \text { VEH } & \text { Vehicle }\end{array}$




\section{References}

1. Marder, S.R.; Cannon, T.D. Schizophrenia. N. Engl. J. Med. 2019, 381, 1753-1761. [CrossRef] [PubMed]

2. American Psychiatric Association. Schizophrenia and other psychotic disorders. In Diagnostic and Statistical Manual of Mental Disorders, 5th ed.; American Psychiatric Association: Washington, DC, USA, 2013.

3. Nielsen, R.E.; Levander, S.; Kjaersdam Telleus, G.; Jensen, S.O.; Ostergaard Christensen, T.; Leucht, S. Second-generation antipsychotic effect on cognition in patients with schizophrenia-A meta-analysis of randomized clinical trials. Acta Psychiatr. Scand. 2015, 131, 185-196. [CrossRef]

4. Abel, K.M.; Drake, R.; Goldstein, J.M. Sex differences in schizophrenia. Int. Rev. Psychiatry 2010, 22, 417-428. [CrossRef] [PubMed]

5. Howard, C.H.; Fiedosewicz, H.; Patel, C.; Klegon, D.A.; Bayog, R.; Berman, I. Treatment response and gender in patients with schizophrenia and schizoaffective disorder. Schizophr. Res. 2001, 49, 232.

6. Uhlhaas, P.J.; Pipa, G.; Lima, B.; Melloni, L.; Neuenschwander, S.; Nikolic, D.; Singer, W. Neural synchrony in cortical networks: History, concept and current status. Front. Integr. Neurosci. 2009, 3, 17. [CrossRef]

7. Vittala, A.; Murphy, N.; Maheshwari, A.; Krishnan, V. Understanding cortical dysfunction in schizophrenia with TMS/EEG. Front. Neurosci. 2020, 14, 554. [CrossRef]

8. Oertel, V.; Knochel, C.; Rotarska-Jagiela, A.; Schonmeyer, R.; Lindner, M.; van de Ven, V.; Haenschel, C.; Uhlhaas, P.; Maurer, K.; Linden, D.E. Reduced laterality as a trait marker of schizophrenia-Evidence from structural and functional neuroimaging. J. Neurosci. 2010, 30, 2289-2299. [CrossRef] [PubMed]

9. Moran, L.V.; Hong, L.E. High vs low frequency neural oscillations in schizophrenia. Schizophr. Bull. 2011, 37, 659-663. [CrossRef]

10. Lodge, D.J.; Behrens, M.M.; Grace, A.A. A Loss of parvalbumin-containing interneurons is associated with diminished oscillatory activity in an animal model of schizophrenia. J. Neurosci. 2009, 29, 2344-2354. [CrossRef]

11. Gonzalez-Burgos, G.; Lewis, D.A. GABA neurons and the mechanisms of network oscillations: Implications for understanding cortical dysfunction in schizophrenia. Schizophr. Bull. 2008, 34, 944-961. [CrossRef]

12. Schmiedt, C.; Brand, A.; Hildebrandt, H.; Basar-Eroglu, C. Event-related theta oscillations during working memory tasks in patients with schizophrenia and healthy controls. Cogn. Brain Res. 2005, 25, 936-947. [CrossRef] [PubMed]

13. Gallinat, J.; Winterer, G.; Herrmann, C.S.; Senkowski, D. Reduced oscillatory gamma-band responses in unmedicated schizophrenic patients indicate impaired frontal network processing. Clin. Neurophysiol. 2004, 115, 1863-1874. [CrossRef]

14. Basar-Eroglu, C.; Brand, A.; Hildebrandt, H.; Karolina Kedzior, K.; Mathes, B.; Schmiedt, C. Working memory related gamma oscillations in schizophrenia patients. Int. J. Psychophysiol. 2007, 64, 39-45. [CrossRef]

15. González-Hernández, J.A.; Cedeño, I.; Pita-Alcorta, C.; Galán, L.; Aubert, E.; Figueredo-RodríGuez, P. Induced oscillations and the distributed cortical sources during the Wisconsin card sorting test performance in schizophrenic patients: New clues to neural connectivity. Int. J. Psychophysiol. 2003, 48, 11-24. [CrossRef]

16. Minzenberg, M.J.; Firl, A.J.; Yoon, J.H.; Gomes, G.C.; Reinking, C.; Carter, C.S. Gamma oscillatory power is impaired during cognitive control independent of medication status in first-episode schizophrenia. Neuropsychopharmacology 2010, 35, 2590-2599. [CrossRef] [PubMed]

17. Ehrlichman, R.S.; Gandal, M.J.; Maxwell, C.R.; Lazarewicz, M.T.; Finkel, L.H.; Contreras, D.; Turetsky, B.I.; Siegel, S.J. N-methyl$\mathrm{d}$-aspartic acid receptor antagonist-induced frequency oscillations in mice recreate pattern of electrophysiological deficits in schizophrenia. Neuroscience 2009, 158, 705-712. [CrossRef]

18. Alegre, M.; Molero, P.; Valencia, M.; Mayner, G.; Ortuño, F.; Artieda, J. Atypical antipsychotics normalize low-gamma evoked oscillations in patients with schizophrenia. Psychiatry Res. 2017, 247, 214-221. [CrossRef]

19. Ahnaou, A.; Huysmans, H.; Van De Casteele, T.; Drinkenburg, W.H.I.M. Cortical high gamma network oscillations and connectivity: A translational index for antipsychotics to normalize aberrant neurophysiological activity. Transl. Psychiatry 2017, 7. [CrossRef]

20. Anderson, P.M.; Pinault, D.; O'Brien, T.J.; Jones, N.C. Chronic administration of antipsychotics attenuates ongoing and ketamineinduced increases in cortical $\gamma$ oscillations. Int. J. Neuropsychopharmacol. 2014, 17, 1895-1904. [CrossRef] [PubMed]

21. Jones, N.C.; Reddy, M.; Anderson, P.; Salzberg, M.R.; O'Brien, T.J.; Pinault, D. Acute administration of typical and atypical antipsychotics reduces EEG gamma power, but only the preclinical compound LY379268 reduces the ketamine-induced rise in gamma power. Int. J. Neuropsychopharmacol. 2012, 15, 657-668. [CrossRef] [PubMed]

22. Foute Nelong, T.; Manduca, J.D.; Zonneveld, P.M.; Perreault, M.L. Asenapine maleate normalizes low frequency oscillatory deficits in a neurodevelopmental model of schizophrenia. Neurosci. Lett. 2019, 711, 134404. [CrossRef]

23. Olszewski, M.; Piasecka, J.; Goda, S.A.; Kasicki, S.; Hunt, M.J. Antipsychotic compounds differentially modulate high-frequency oscillations in the rat nucleus accumbens: A comparison of first- and second-generation drugs. Int. J. Neuropsychopharmacol. 2013, 16, 1009-1020. [CrossRef]

24. Haddad, P.; Brain, C.; Scott, J. Nonadherence with antipsychotic medication in schizophrenia: Challenges and management strategies. Patient Relat. Outcome Meas. 2014, 5, 43-62. [CrossRef]

25. Takeuchi, H.; Suzuki, T.; Remington, G.; Bies, R.R.; Abe, T.; Graff-Guerrero, A.; Watanabe, K.; Mimura, M.; Uchida, H. Effects of risperidone and olanzapine dose reduction on cognitive function in stable patients with schizophrenia: An open-label, randomized, controlled, pilot study. Schizophr. Bull. 2013, 39, 993-998. [CrossRef] [PubMed]

26. Haddad, P.M.; Sharma, S.G. Adverse effects of atypical antipsychotics. CNS Drugs 2007, 21, 911-936. [CrossRef] 
27. Acosta, F.J.; Bosch, E.; Sarmiento, G.; Juanes, N.; Caballero-Hidalgo, A.; Mayans, T. Evaluation of noncompliance in schizophrenia patients using electronic monitoring $\left(\mathrm{MEMS}^{\circledR}\right)$ and its relationship to sociodemographic, clinical and psychopathological variables. Schizophr. Res. 2009, 107, 213-217. [CrossRef]

28. Löffler, W.; Kilian, R.; Toumi, M.; Angermeyer, M.C. Schizophrenic patients' subjective reasons for compliance and noncompliance with neuroleptic treatment. Pharmacopsychiatry 2003, 36, 105-112. [CrossRef]

29. Liu-Seifert, H.; Osuntokun, O.O.; Feldman, P.D. Factors associated with adherence to treatment with olanzapine and other atypical antipsychotic medications in patients with schizophrenia. Compr. Psychiatry 2012, 53, 107-115. [CrossRef]

30. Bumb, J.M.; Enning, F.; Leweke, F.M. Drug repurposing and emerging adjunctive treatments for schizophrenia. Expert Opin. Pharmacother. 2015, 16, 1049-1067. [CrossRef] [PubMed]

31. Davies, C.; Bhattacharyya, S. Cannabidiol as a potential treatment for psychosis. Ther. Adv. Psychopharmacol. 2019, 9. [CrossRef] [PubMed]

32. Gururajan, A.; Malone, D.T. Does cannabidiol have a role in the treatment of schizophrenia? Schizophr. Res. 2016, 176, 281-290. [CrossRef] [PubMed]

33. Leweke, F.M.; Piomelli, D.; Pahlisch, F.; Muhl, D.; Gerth, C.W.; Hoyer, C.; Klosterkötter, J.; Hellmich, M.; Koethe, D. Cannabidiol enhances anandamide signaling and alleviates psychotic symptoms of schizophrenia. Transl. Psychiatry 2012, 2, e94. [CrossRef]

34. Mcguire, P.; Robson, P.; Cubala, W.J.; Vasile, D.; Morrison, P.D.; Barron, R.; Taylor, A.; Wright, S. Cannabidiol (CBD) as an adjunctive therapy in schizophrenia: A multicenter randomized controlled trial. Am. J. Psychiatry 2018, 175, 225-231. [CrossRef] [PubMed]

35. Makiol, C.; Kluge, M. Remission of severe, treatment-resistant schizophrenia following adjunctive cannabidiol. Aust. New Zealand J. Psychiatry 2019, 53, 262. [CrossRef] [PubMed]

36. Boggs, D.L.; Surti, T.; Gupta, A.; Gupta, S.; Niciu, M.; Pittman, B.; Schnakenberg Martin, A.M.; Thurnauer, H.; Davies, A.; D’Souza, D.C.; et al. The effects of cannabidiol (CBD) on cognition and symptoms in outpatients with chronic schizophrenia a randomized placebo controlled trial. Psychopharmacology 2018, 235, 1923-1932. [CrossRef]

37. Kathuria, A.; Lopez-Lengowski, K.; Watmuff, B.; Mcphie, D.; Cohen, B.M.; Karmacharya, R. Synaptic deficits in iPSC-derived cortical interneurons in schizophrenia are mediated by NLGN2 and rescued by N-acetylcysteine. Transl. Psychiatry 2019, 9. [CrossRef] [PubMed]

38. Schrode, N.; Ho, S.-M.; Yamamuro, K.; Dobbyn, A.; Huckins, L.; Matos, M.R.; Cheng, E.; Deans, P.J.M.; Flaherty, E.; Barretto, N.; et al. Synergistic effects of common schizophrenia risk variants. Nat. Genet. 2019, 51, 1475-1485. [CrossRef]

39. Wang, X.; Ye, F.; Wen, Z.; Guo, Z.; Yu, C.; Huang, W.-K.; Rojas Ringeling, F.; Su, Y.; Zheng, W.; Zhou, G.; et al. Structural interaction between DISC1 and ATF4 underlying transcriptional and synaptic dysregulation in an iPSC model of mental disorders. Mol. Psychiatry 2019, 26, 1346-1360. [CrossRef]

40. Sarkar, A.; Mei, A.; Paquola, A.C.M.; Stern, S.; Bardy, C.; Klug, J.R.; Kim, S.; Neshat, N.; Kim, H.J.; Ku, M.; et al. Efficient generation of CA3 neurons from human pluripotent stem cells enables modeling of hippocampal connectivity in vitro. Cell Stem Cell 2018, 22, 684-697.e689. [CrossRef] [PubMed]

41. MacLaren, E.J.; Charlesworth, P.; Coba, M.P.; Grant, S.G.N. Knockdown of mental disorder susceptibility genes disrupts neuronal network physiology in vitro. Mol. Cell. Neurosci. 2011, 47, 93-99. [CrossRef] [PubMed]

42. Flaherty, E.; Deranieh, R.M.; Artimovich, E.; Lee, I.S.; Siegel, A.J.; Levy, D.L.; Nestor, M.W.; Brennand, K.J. Patient-derived hiPSC neurons with heterozygous CNTNAP2 deletions display altered neuronal gene expression and network activity. NPJ Schizophr. 2017, 3. [CrossRef]

43. Ramsey, J.M.; Schwarz, E.; Guest, P.C.; Van Beveren, N.J.M.; Leweke, F.M.; Rothermundt, M.; Bogerts, B.; Steiner, J.; Bahn, S. Distinct molecular phenotypes in male and female schizophrenia patients. PLoS ONE 2013, 8, e78729. [CrossRef] [PubMed]

44. Goldstein, J.M.; Cherkerzian, S.; Tsuang, M.T.; Petryshen, T.L. Sex differences in the genetic risk for schizophrenia: History of the evidence for sex-specific and sex-dependent effects. Am. J. Med. Genet. Part B Neuropsych. Genet. 2013, 162, 698-710. [CrossRef]

45. Aleman, A.; Kahn, R.S.; Selten, J.-P. Sex differences in the risk of schizophrenia. Arch. Gen. Psychiatry 2003, 60, 565. [CrossRef]

46. Usall, J.; Suarez, D.; Haro, J.M. Gender differences in response to antipsychotic treatment in outpatients with schizophrenia. Psychiatry Res. 2007, 153, 225-231. [CrossRef]

47. Seeman, M.V. Men and women respond differently to antipsychotic drugs. Neuropharmacology 2020, 163, 107631. [CrossRef]

48. Hui, C.W.; St-Pierre, A.; El Hajj, H.; Remy, Y.; Hébert, S.S.; Luheshi, G.N.; Srivastava, L.K.; Tremblay, M.-È. Prenatal immune challenge in mice leads to partly sex-dependent behavioral, microglial, and molecular abnormalities associated with schizophrenia. Front. Mol. Neurosci. 2018, 11. [CrossRef]

49. Chalkiadaki, K.; Velli, A.; Kyriazidis, E.; Stavroulaki, V.; Vouvoutsis, V.; Chatzaki, E.; Aivaliotis, M.; Sidiropoulou, K. Development of the MAM model of schizophrenia in mice: Sex similarities and differences of hippocampal and prefrontal cortical function. Neuropharmacology 2019, 144, 193-207. [CrossRef]

50. Bristow, G.C.; Bostrom, J.A.; Haroutunian, V.; Sodhi, M.S. Sex differences in GABAergic gene expression occur in the anterior cingulate cortex in schizophrenia. Schizophr. Res. 2015, 167, 57-63. [CrossRef]

51. Kaar, S.J.; Angelescu, I.; Marques, T.R.; Howes, O.D. Pre-frontal parvalbumin interneurons in schizophrenia: A meta-analysis of post-mortem studies. J. Neural. Transm. 2019, 126, 1637-1651. [CrossRef]

52. Perez, S.M.; Donegan, J.J.; Lodge, D.J. Effect of estrous cycle on schizophrenia-like behaviors in MAM exposed rats. Behav. Brain Res. 2019, 362, 258-265. [CrossRef] [PubMed] 
53. Cooper, Z.D.; Craft, R.M. Sex-dependent effects of cannabis and cannabinoids: A translational perspective. Neuropsychopharmacology 2018, 43, 34-51. [CrossRef]

54. Anderson, D.E.; Madhavan, D.; Swaminathan, A. Global brain network dynamics predict therapeutic responsiveness to cannabidiol treatment for refractory epilepsy. Brain Commun. 2020. [CrossRef] [PubMed]

55. Bhattacharyya, S.; Falkenberg, I.; Martin-Santos, R.; Atakan, Z.; Crippa, J.A.; Giampietro, V.; Brammer, M.; Mcguire, P. Cannabinoid modulation of functional connectivity within regions processing attentional salience. Neuropsychopharmacology 2015, 40, 1343-1352. [CrossRef]

56. Linge, R.; Jiménez-Sánchez, L.; Campa, L.; Pilar-Cuéllar, F.; Vidal, R.; Pazos, A.; Adell, A.; Díaz, Á. Cannabidiol induces rapid-acting antidepressant-like effects and enhances cortical 5-HT/glutamate neurotransmission: Role of 5-HT1A receptors. Neuropharmacology 2016, 103, 16-26. [CrossRef]

57. Sales, A.J.; Fogaça, M.V.; Sartim, A.G.; Pereira, V.S.; Wegener, G.; Guimarães, F.S.; Joca, S.R.L. Cannabidiol induces rapid and sustained antidepressant-like effects through increased BDNF signaling and synaptogenesis in the prefrontal cortex. Mol. Neurobiol. 2019, 56, 1070-1081. [CrossRef]

58. Hallak, J.E.C.; Machado-De-Sousa, J.P.; Crippa, J.A.S.; Sanches, R.F.; Trzesniak, C.; Chaves, C.; Bernardo, S.A.; Regalo, S.C.; Zuardi, A.W. Performance of schizophrenic patients in the Stroop Color Word Test and electrodermal responsiveness after acute administration of cannabidiol (CBD). Rev. Bras. Psiquiatr. 2010, 32, 56-61. [CrossRef] [PubMed]

59. Gururajan, A.; Taylor, D.A.; Malone, D.T. Cannabidiol and clozapine reverse MK-801-induced deficits in social interaction and hyperactivity in Sprague-Dawley rats. J. Psychopharmacol. 2012, 26, 1317-1332. [CrossRef]

60. Gomes, F.V.; Llorente, R.; Del Bel, E.A.; Viveros, M.-P.; López-Gallardo, M.; Guimarães, F.S. Decreased glial reactivity could be involved in the antipsychotic-like effect of cannabidiol. Schizophr. Res. 2015, 164, 155-163. [CrossRef] [PubMed]

61. Osborne, A.L.; Solowij, N.; Babic, I.; Huang, X.-F.; Weston-Green, K. Improved social interaction, recognition and working memory with cannabidiol treatment in a prenatal infection (poly I:C) rat model. Neuropsychopharmacology 2017, 42, 1447-1457. [CrossRef]

62. Long, L.E.; Chesworth, R.; Huang, X.-F.; Wong, A.; Spiro, A.; Mcgregor, I.S.; Arnold, J.C.; Karl, T. Distinct neurobehavioural effects of cannabidiol in transmembrane domain neuregulin 1 mutant mice. PLoS ONE 2012, 7, e34129. [CrossRef]

63. Görtz, P.; Henning, U.; Theiss, S.; Lange-Asschenfeldt, C. Effect fingerprints of antipsychotic drugs on neural networks in vitro. J. Neural Transm. 2019, 126, 1363-1371. [CrossRef]

64. Dzyubenko, E.; Juckel, G.; Faissner, A. The antipsychotic drugs olanzapine and haloperidol modify network connectivity and spontaneous activity of neural networks in vitro. Sci. Rep. 2017, 7. [CrossRef]

65. Gottschling, C.; Geissler, M.; Springer, G.; Wolf, R.; Juckel, G.; Faissner, A. First and second generation antipsychotics differentially affect structural and functional properties of rat hippocampal neuron synapses. Neuroscience 2016, 337, 117-130. [CrossRef]

66. Nordström, A.-L.; Farde, L.; Halldin, C. Time course of D2-dopamine receptor occupancy examined by PET after single oral doses of haloperidol. Psychopharmacology 1992, 106, 433-438. [CrossRef]

67. Tauscher, J.; Jones, C.; Remington, G.; Zipursky, R.B.; Kapur, S. Significant dissociation of brain and plasma kinetics with antipsychotics. Mol. Psychiatry 2002, 7, 317-321. [CrossRef]

68. Kapur, S.; Arenovich, T.; Agid, O.; Zipursky, R.; Lindborg, S.; Jones, B. Evidence for onset of antipsychotic effects within the first 24 hours of treatment. Am. J. Psychiatry 2005, 162, 939-946. [CrossRef]

69. Huang, X.-F.; Song, X. Effects of antipsychotic drugs on neurites relevant to schizophrenia treatment. Med. Res. Rev. 2019, 39, 386-403. [CrossRef]

70. Critchlow, H.M.; Maycox, P.R.; Skepper, J.N.; Krylova, O. Clozapine and haloperidol differentially regulate dendritic spine formation and synaptogenesis in rat hippocampal neurons. Mol. Cell. Neurosci. 2006, 32, 356-365. [CrossRef]

71. Park, S.W.; Lee, C.H.; Cho, H.Y.; Seo, M.K.; Lee, J.G.; Lee, B.J.; Seol, W.; Kee, B.S.; Kim, Y.H. Effects of antipsychotic drugs on the expression of synaptic proteins and dendritic outgrowth in hippocampal neuronal cultures. Synapse 2013, 67, 224-234. [CrossRef]

72. Bowling, H.; Zhang, G.; Bhattacharya, A.; Perez-Cuesta, L.M.; Deinhardt, K.; Hoeffer, C.A.; Neubert, T.A.; Gan, W.-B.; Klann, E.; Chao, M.V. Antipsychotics activate mTORC1-dependent translation to enhance neuronal morphological complexity. Sci. Signal. 2014, 7, ra4. [CrossRef]

73. Krichmar, J.L.; Nasuto, S.J.; Scorcioni, R.; Washington, S.D.; Ascoli, G.A. Effects of dendritic morphology on CA3 pyramidal cell electrophysiology: A simulation study. Brain Res. 2002, 941, 11-28. [CrossRef]

74. Zhu, G.; Du, L.; Jin, L.; Offenhäusser, A. Effects of morphology constraint on electrophysiological properties of cortical neurons. Sci. Rep. 2016, 6, 23086. [CrossRef] [PubMed]

75. Van Elburg, R.A.J.; Van Ooyen, A. Impact of dendritic size and dendritic topology on burst firing in pyramidal cells. PLoS Comput. Biol. 2010, 6, e1000781. [CrossRef]

76. Elsworth, J.D.; Morrow, B.A.; Hajszan, T.; Leranth, C.; Roth, R.H. Phencyclidine-induced loss of asymmetric spine synapses in rodent prefrontal cortex is reversed by acute and chronic treatment with olanzapine. Neuropsychopharmacology 2011, 36, 2054-2061. [CrossRef] [PubMed]

77. De Bartolomeis, A.; Buonaguro, E.F.; Latte, G.; Rossi, R.; Marmo, F.; Iasevoli, F.; Tomasetti, C. Immediate-early genes modulation by antipsychotics: Translational implications for a putative gateway to drug-induced long-term brain changes. Front. Behav. Neurosci. 2017, 11. [CrossRef] [PubMed] 
78. Khandaker, G.M.; Cousins, L.; Deakin, J.; Lennox, B.R.; Yolken, R.; Jones, P.B. Inflammation and immunity in schizophrenia: Implications for pathophysiology and treatment. Lancet Psychiatry 2015, 2, 258-270. [CrossRef]

79. Na, K.-S.; Jung, H.-Y.; Kim, Y.-K. The role of pro-inflammatory cytokines in the neuroinflammation and neurogenesis of schizophrenia. Prog. Neuro Psychopharmacol. Biol. Psychiatry 2014, 48, 277-286. [CrossRef] [PubMed]

80. Monji, A.; Kato, T.; Kanba, S. Cytokines and schizophrenia: Microglia hypothesis of schizophrenia. Psychiatry Clin. Neurosci. 2009, 63, 257-265. [CrossRef]

81. Miller, B.J.; Buckley, P.; Seabolt, W.; Mellor, A.; Kirkpatrick, B. Meta-Analysis of cytokine alterations in schizophrenia: Clinical status and antipsychotic effects. Biol. Psychiatry 2011, 70, 663-671. [CrossRef]

82. Campos, A.C.; Fogaça, M.V.; Scarante, F.F.; Joca, S.R.L.; Sales, A.J.; Gomes, F.V.; Sonego, A.B.; Rodrigues, N.S.; Galve-Roperh I.; Guimarães, F.S. Plastic and neuroprotective mechanisms Involved in the therapeutic effects of cannabidiol in psychiatric disorders. Front. Pharmacol. 2017, 8. [CrossRef]

83. Esposito, G.; Scuderi, C.; Valenza, M.; Togna, G.I.; Latina, V.; De Filippis, D.; Cipriano, M.; Carratù, M.R.; Iuvone, T.; Steardo, L. Cannabidiol reduces A $\beta$-induced neuroinflammation and promotes hippocampal neurogenesis through PPAR $\gamma$ involvement. PLoS ONE 2011, 6, e28668. [CrossRef]

84. Kato, T.; Monji, A.; Hashioka, S.; Kanba, S. Risperidone significantly inhibits interferon- $\gamma$-induced microglial activation in vitro. Schizophr. Res. 2007, 92, 108-115. [CrossRef]

85. Kozela, E.; Pietr, M.; Juknat, A.; Rimmerman, N.; Levy, R.; Vogel, Z. Cannabinoids $\Delta$ 9-tetrahydrocannabinol and cannabidiol differentially inhibit the lipopolysaccharide-activated NF- $\kappa B$ and interferon- $\beta /$ STAT proinflammatory pathways in BV-2 microglial cells. J. Biol. Chem. 2010, 285, 1616-1626. [CrossRef]

86. Obuchowicz, E.; Bielecka-Wajdman, A.M.; Paul-Samojedny, M.; Nowacka, M. Different influence of antipsychotics on the balance between pro- and anti-inflammatory cytokines depends on glia activation: An in vitro study. Cytokine 2017, 94, 37-44. [CrossRef]

87. Sugino, H.; Futamura, T.; Mitsumoto, Y.; Maeda, K.; Marunaka, Y. Atypical antipsychotics suppress production of proinflammatory cytokines and up-regulate interleukin-10 in lipopolysaccharide-treated mice. Prog. Neuro Psychopharmacol. Biol. Psychiatry 2009, 33, 303-307. [CrossRef]

88. Monji, A.; Kato, T.A.; Mizoguchi, Y.; Horikawa, H.; Seki, Y.; Kasai, M.; Yamauchi, Y.; Yamada, S.; Kanba, S. Neuroinflammation in schizophrenia especially focused on the role of microglia. Prog. Neuro Psychopharmacol. Biol. Psychiatry 2013, 42, 115-121. [CrossRef]

89. Prieto, G.A.; Cotman, C.W. Cytokines and cytokine networks target neurons to modulate long-term potentiation. Cytokine Growth Factor Rev. 2017, 34, 27-33. [CrossRef]

90. Prieto, G.A.; Tong, L.; Smith, E.D.; Cotman, C.W. TNF $\alpha$ and IL-1 $\beta$ but not IL-18 suppresses hippocampal long-term potentiation directly at the synapse. Neurochem. Res. 2019, 44, 49-60. [CrossRef]

91. Clarkson, B.D.S.; Kahoud, R.J.; Mccarthy, C.B.; Howe, C.L. Inflammatory cytokine-induced changes in neural network activity measured by waveform analysis of high-content calcium imaging in murine cortical neurons. Sci. Rep. 2017, 7. [CrossRef]

92. Perea, G.; Navarrete, M.; Araque, A. Tripartite synapses: Astrocytes process and control synaptic information. Trends Neurosci. 2009, 32, 421-431. [CrossRef]

93. Araque, A.; Navarrete, M. Glial cells in neuronal network function. Philos. Trans. R. Soc. Lond. B Biol. Sci. 2010, 365, $2375-2381$. [CrossRef]

94. Badimon, A.; Strasburger, H.J.; Ayata, P.; Chen, X.; Nair, A.; Ikegami, A.; Hwang, P.; Chan, A.T.; Graves, S.M.; Uweru, J.O.; et al. Negative feedback control of neuronal activity by microglia. Nature 2020, 586, 417-423. [CrossRef]

95. Béchade, C.; Cantaut-Belarif, Y.; Bessis, A. Microglial control of neuronal activity. Front. Cell. Neurosci. 2013, 7. [CrossRef] [PubMed]

96. York, E.M.; Bernier, L.-P.; MacVicar, B.A. Microglial modulation of neuronal activity in the healthy brain. Dev. Neurobiol. 2018, 78, 593-603. [CrossRef]

97. Stellwagen, D.; Malenka, R.C. Synaptic scaling mediated by glial TNF- $\alpha$. Nature 2006, 440, 1054-1059. [CrossRef] [PubMed]

98. Metna-Laurent, M.; Marsicano, G. Rising stars: Modulation of brain functions by astroglial type-1 cannabinoid receptors. Glia 2015, 63, 353-364. [CrossRef]

99. Navarrete, M.; Araque, A. Endocannabinoids mediate neuron-astrocyte communication. Neuron 2008, 57, 883-893. [CrossRef]

100. D'Addario, C.; Micale, V.; Di Bartolomeo, M.; Stark, T.; Pucci, M.; Sulcova, A.; Palazzo, M.; Babinska, Z.; Cremaschi, L.; Drago, F.; et al. A preliminary study of endocannabinoid system regulation in psychosis: Distinct alterations of CNR1 promoter DNA methylation in patients with schizophrenia. Schizophr. Res. 2017, 188, 132-140. [CrossRef] [PubMed]

101. Flaum, M.; Swayze, V.W., 2nd; O’Leary, D.S.; Yuh, W.T.; Ehrhardt, J.C.; Arndt, S.V.; Andreasen, N.C. Effects of diagnosis, laterality, and gender on brain morphology in schizophrenia. Am. J. Psychiatry 1995, 152, 704-714. [CrossRef]

102. Agid, O.; Seeman, P.; Kapur, S. The "delayed onset" of antipsychotic action-An idea whose time has come and gone. J. Psychiatry Neurosci. 2006, 31, 93-100. [PubMed]

103. Drysdale, A.J.; Ryan, D.; Pertwee, R.G.; Platt, B. Cannabidiol-induced intracellular Ca ${ }^{2+}$ elevations in hippocampal cells. Neuropharmacology 2006, 50, 621-631. [CrossRef] [PubMed]

104. Perreault, M.L.; Hasbi, A.; Alijaniaram, M.; O’Dowd, B.F.; George, S.R. Reduced striatal dopamine D1-D2 receptor heteromer expression and behavioural subsensitivity in juvenile rats. Neuroscience 2012, 225, 130-139. [CrossRef] [PubMed] 